DOI: $10.1002 / \mathrm{adfm} .201701818$

\title{
Copper(I) Thiocyanate (CuSCN) Hole-Transport Layers Processed from Aqueous Precursor Solutions and Their Application in Thin-Film Transistors and Highly Efficient Organic and Organometal Halide Perovskite Solar Cells
}

Nilushi Wijeyasinghe, Anna Regoutz, Flurin Eisner, Tian Du, Leonidas Tsetseris, Yen-Hung Lin, Hendrik Faber, Pichaya Pattanasattayavong, Jinhua Li, Feng Yan, Martyn A. McLachlan, David J. Payne, Martin Heeney and Thomas D. Anthopoulos*

N. Wijeyasinghe, F. Eisner, Dr. Y.-H. Lin, Dr. H. Faber, Prof. T. D. Anthopoulos Department of Physics and The Centre for Plastic Electronics Imperial College London London SW7 2AZ, UK

Dr. A. Regoutz, T. Du, Dr. D. J. Payne, Dr. M. A. McLachlan

Department of Materials and The Centre for Plastic Electronics Imperial College London Royal School of Mines, London SW7 2AZ, UK

Prof. L. Tsetseris

Department of Physics

National Technical University of Athens

Athens GR-15780, Greece

Dr. P. Pattanasattayavong

Department of Materials Science and Engineering

School of Molecular Science and Engineering Vidyasirimedhi Institute of Science and Technology (VISTEC)

Rayong 21210, Thailand

Dr. J. Li, Prof. F. Yan

Department of Applied Physics

The Hong Kong Polytechnic University

Hung Hom, Kowloon, Hong Kong

Prof. M. Heeney

Department of Chemistry and The Centre for Plastic Electronics

Imperial College London, London SW7 2AZ, UK

Prof. T. D. Anthopoulos

Materials Science and Engineering, Division of Physical Sciences and Engineering King Abdullah University of Science and Technology

Thuwal 23955-6900, Saudi Arabia

E-mail: thomas.anthopoulos@kaust.edu.sa

Keywords: Copper(I) thiocyanate; hole transport layers; organic solar cells; perovskite solar cells; transparent semiconductors and transistors 


\section{Abstract}

We report the development of copper(I) thiocyanate $(\mathrm{CuSCN})$ hole-transport layers (HTLs) processed from aqueous ammonia as a novel alternative to conventional n-alkyl sulfide solvents. Wide-bandgap (3.4-3.9eV) and ultrathin (3-5nm) layers of $\mathrm{CuSCN}$ are formed when the aqueous $\mathrm{CuSCN}$-ammine complex solution is spin-cast in air and annealed at $100{ }^{\circ} \mathrm{C}$. X-ray photoelectron spectroscopy confirms the high compositional purity of the formed CuSCN layers, while the high-resolution valence band spectra agree with first-principles calculations. Study of the hole transport properties using field-effect transistor measurements reveal that the aqueous-processed CuSCN layers exhibit a fivefold higher hole mobility than films processed from diethyl sulphide solutions with the maximum values approaching $0.1 \mathrm{~cm}^{2} \mathrm{~V}^{-1} \mathrm{~s}^{-1}$. A further interesting characteristic is the low surface roughness of the resulting $\mathrm{CuSCN}$ layers, which in the case of solar cells helps to planarize the indium-tin-oxide anode. Organic bulkheterojunction and planar organometal halide perovskite solar cells based on aqueousprocessed CuSCN HTLs yield power conversion efficiency of $10.7 \%$ and $17.5 \%$, respectively. Importantly, CuSCN-based cells consistently outperform devices based on poly $(3,4-$ ethylenedioxythiophene) polystyrene sulfonate HTLs. This is the first report on CuSCN and devices processed via an aqueous-based synthetic route that is compatible with high-throughput manufacturing and paves the way for further developments.

\section{Introduction}

Copper(I) thiocyanate $(\mathrm{CuSCN})$ is an inorganic, wide-bandgap $(>3.4 \mathrm{eV}),{ }^{[1,2]}$ molecular semiconductor that combines excellent hole-transport ( $p$-type) characteristics with high optical transparency and attractive mechanical properties. ${ }^{[2-4]}$ The use of CuSCN as the hole-transport layer (HTL) has been demonstrated in numerous emerging opto/electronic applications, ${ }^{[5]}$ including thin-film transistors (TFTs) and integrated circuits, ${ }^{[2,4,6]}$ organic photovoltaic (OPV) 
cells, ${ }^{[7,8]}$ hybrid perovskite solar cells,${ }^{\left[{ }^{[-11]}\right.}$ and organic light emitting diodes (OLEDs). ${ }^{[12,13]}$ $\mathrm{CuSCN}$ can be deposited at low-temperature using a range of solution-processing methods, which include spin-casting, ${ }^{[2,6,7]}$ ink-jet printing, ${ }^{[14,15]}$ doctor blading, ${ }^{[16]}$ spray coating,,${ }^{[17,18]}$ and electrochemical deposition. ${ }^{[19-21]}$ The processing versatility of CuSCN on the other hand enables its combination with inexpensive, and often temperature sensitive, substrate materials such as plastic. ${ }^{[22]}$ These attractive physical attributes combined with its low cost and commercial availability make $\mathrm{CuSCN}$ a promising alternative to traditional inorganic/organic HTL materials.

Alternative materials that combine the processing versatility of $\mathrm{CuSCN}$ with the $p$-type character include various metal oxides such as copper oxide $\left(\mathrm{Cu}_{2} \mathrm{O}\right)$, tin monoxide $(\mathrm{SnO})$ and nickel oxide (NiO). ${ }^{[23-25]}$ Although thin-film transistors (TFTs) based on these materials have shown to exhibit hole mobilities of $>1 \mathrm{~cm}^{2} \mathrm{~V}^{-1} \mathrm{~s}^{-1},{ }^{[23,24,26]}$ their relatively small bandgap $\left(\mathrm{Cu}_{2} \mathrm{O}\right.$, $\mathrm{SnO})^{[27-29]}$ yields layers with low transparency, while the high temperature processing that often is required ${ }^{[26,30]}$ renders them incompatible with inexpensive temperature-sensitive substrate materials such as plastic. The use of organic HTLs, such as poly(3,4-ethylenedioxythiophene) polystyrene sulfonate (PEDOT:PSS), has been exploited to address some of these concerns but, in many cases, at the expense of the devices' operating stability. ${ }^{[31-33]}$ A further disadvantage of PEDOT:PSS is its semi-metallic nature, which does not prevent electron flow to the anode; an important efficiency loss process for various organic optoelectronic devices (e.g. OPVs, OLEDs). ${ }^{[4-7]}$ Consequently, there is a continuous demand for wide-bandgap $p$-type semiconductors that combine solubility, optical transparency, high hole mobility and low temperature processing.

It was only recently that the use of $\mathrm{CuSCN}$ as the HTL material was shown to yield optoelectronic devices with improved efficiency and lifetime. ${ }^{[7]}$ Despite these promising early results, however, processing of $\mathrm{CuSCN}$ is still challenging as it is largely insoluble in the vast majority of common solvents, with sulphur-based solvents being the most effective and widely 
studied. ${ }^{[7,34]}$ This limitation restricts $\mathrm{CuSCN}$ processing to enclosed and strictly controlled laboratory environments due to the strong odour, although no evidence of $\mathrm{CuSCN}$ posing risks to human health are known. ${ }^{[35]}$ Therefore, successful application of $\mathrm{CuSCN}$ in the emerging sector of large-area optoelectronics would most certainly require the development of alternative and environmentally-friendly solvents. While reports on alternative organic solvents such as dimethyl sulfoxide do exist, the power conversion efficiencies achieved have been limited $(<5 \%)$ by the high surface roughness of the resulting $\mathrm{CuSCN}$ layer. ${ }^{[36]}$

Here we report the development of transparent hole-transporting CuSCN layers via spin casting in ambient air from aqueous ammonia $\left[\mathrm{NH}_{3}(\mathrm{aq})\right]$ solution [denoted as $\mathrm{CuSCN} / \mathrm{NH}_{3}(\mathrm{aq})$ ] and their application in $p$-type transistors and high efficiency solar cells. Chemical studies on CuSCN networks, ${ }^{[37-40]}$ which utilized aqueous ammonia as the solvent, and detailed the formation of copper complexes in solution, provided the starting point for this work. The structural, optical and electronic properties of the ammonia-processed CuSCN layers were studied and contrasted with those processed from diethyl sulphide (DES) solution under inert atmosphere. $\mathrm{CuSCN}$ transistors processed from $\mathrm{NH}_{3}(\mathrm{aq})$ solution exhibit superior hole transport, as compared to devices processed from DES, with mobility values approaching $\sim 0.1 \mathrm{~cm}^{2} / \mathrm{Vs}$. Incorporation of the ammonia-processed CuSCN as the HTLs in bulk-heterojunction organic and planar organometal halide perovskite solar cells, leads to devices with power conversion efficiency (PCE) of up to $10.7 \%$ and $17.5 \%$, respectively. To the best of our knowledge, this is the first demonstration of high performance solution-processed optoelectronic devices where $\mathrm{CuSCN}$ is deposited from an aqueous solvent formulation that is inexpensive and compatible with large-area manufacturing.

\section{Optical Characterization of CuSCN Solutions and Solid Layers}


Following the careful optimization of deposition parameters, highly uniform and ultrathin $\mathrm{CuSCN}$ layers were spin-cast on quartz substrates from the aqueous formulation. Typically, $\mathrm{CuSCN}$ forms colourless solutions when dissolved in n-alkyl sulphide solvents, such as the DES reference solvent used in this study. On the contrary, a deep blue CuSCN-ammine complex formed when the white $\mathrm{CuSCN}$ powder was added and stirred for 1 hour at $50{ }^{\circ} \mathrm{C}$ in aqueous ammonia at concentrations of $10-15 \mathrm{mg} \mathrm{ml}^{-1}$. Figure 1a shows photographs of the $\mathrm{CuSCN} / \mathrm{NH}_{3}(\mathrm{aq})$ and $\mathrm{CuSCN} / \mathrm{DES}$ solutions. Small quantities of a precipitate were observed in the solutions after 1 hour cooling to ambient temperature $\left(\sim 20^{\circ} \mathrm{C}\right)$. The precipitates are attributed partly to differences in the solubility of $\mathrm{CuSCN}$ in aqueous ammonia at lower temperatures and partly to the presence of other copper-based compounds (e.g. copper oxide), which can form as products of redox reactions. For this reason, all solutions were filtered prior to spin coating and thermal annealing at $100{ }^{\circ} \mathrm{C}$.

Figure 1b shows the ultraviolet-visible-near-infrared (UV-Vis-NIR) absorbance spectra of the $\mathrm{CuSCN}$-containing solutions together with those of the solid films for comparison. While the absorbance of the CuSCN/DES solution only differed marginally from that of the solvent, significant differences between the $\mathrm{NH}_{3}(\mathrm{aq})$ and $\mathrm{CuSCN} / \mathrm{NH}_{3}(\mathrm{aq})$ solutions can be observed due to the complexation chemistry of the latter. Despite this, the ammonia-processed layer exhibits the characteristic CuSCN spectrum, and notably, lacks the absorption features associated with the narrow-bandgap nature of copper oxides. Further consideration of the layer composition leads to the hypothesis that $\mathrm{Cu}(\mathrm{SCN})_{2}$ could only be present as a minority contaminant because the compound rapidly converts to $\mathrm{CuSCN}$ in aqueous environment and at elevated temperatures. ${ }^{[1,42]}$ The latter hypothesis is experimentally verified by XPS analysis and will be discussed in Section 5 .

Figure 1c shows the Tauc plots from which the optical bandgap (EOPT) of the $\mathrm{CuSCN} / \mathrm{NH}_{3}(\mathrm{aq})$ processed layer was extracted. Here, $(\alpha h v)^{\mathrm{n}}$ is plotted versus incident photon energy $(h v)$, where $\alpha$ is the absorption coefficient, $h$ is Planck's constant, $v$ is radiation 
frequency, and $\mathrm{n}$ is equal to 0.5 for an indirect bandgap semiconductor and 2 for a direct bandgap semiconductor. Linear fits applied to the appropriate regions of the plots yield values of $3.45( \pm 0.05)$ and $3.85( \pm 0.05) \mathrm{eV}$ for the indirect and direct bandgap, respectively. Similarly, spectra from a DES-processed layer yields $E_{\mathrm{OPT}}$ values of $3.40( \pm 0.05)$ (indirect) and 3.85 $( \pm 0.05)$ eV (direct) (Figure S1, Supporting Information). These results are consistent with data reported in the literature for $\mathrm{CuSCN} .^{[1,20,43-45]}$

The colour of the solution formed when $\mathrm{Cu}(\mathrm{I}) \mathrm{SCN}$ dissolves in $\mathrm{NH}_{3}(\mathrm{aq})$ is expected to arise from the formation of a $\mathrm{Cu}^{2+}$-ammine complex, which is widely reported to exhibit a characteristic blue colour. ${ }^{[46-48]}$ If this assumption is correct, a $\mathrm{Cu}(\mathrm{II})$ compound could be utilized as a source of $\mathrm{Cu}^{2+}$ ions for the deposition of $\mathrm{CuSCN}$ from an ammonia-based solution where $\mathrm{SCN}^{-}$ions are also present. To test this hypothesis an experiment to investigate the complexation chemistry of the $\mathrm{CuSCN} / \mathrm{NH}_{3}(\mathrm{aq})$ solution was conducted. For this, a mixture of copper(II) oxide $(\mathrm{CuO})$ and ammonium thiocyanate $\left(\mathrm{NH}_{4} \mathrm{SCN}\right)$ was dissolved in aqueous ammonia at a 1:1 molar ratio; a deep blue saturated solution similar to that observed with the $\mathrm{Cu}(\mathrm{I}) \mathrm{SCN}$ precursor (Figure 1a) was formed. Figure S2 in Supporting Information section shows the UV-Vis-NIR transmittance spectra for the ammonia-based solutions containing $\mathrm{CuO}$ and $\mathrm{NH}_{4} \mathrm{SCN}$. A broad transmittance peak corresponding to one observed at the $300-500 \mathrm{~nm}$ spectral region of the $\mathrm{CuSCN} / \mathrm{NH}_{3}(\mathrm{aq})$ solution spectrum was detected for $\mathrm{CuO} / \mathrm{NH}_{3}(\mathrm{aq})$, which revealed that the colour observed upon dissolution of $\mathrm{CuSCN}$ in aqueous ammonia did indeed originate from an ammine complex containing $\mathrm{Cu}^{2+}$ ions. Notably, despite $\mathrm{CuO}$ being a low bandgap material, the layers spin-cast from a precursor mixture containing $\mathrm{NH}_{4} \mathrm{SCN}$ were optically transparent and exhibited the characteristic $\mathrm{CuSCN}$ absorption spectrum. Tauc analysis of the absorption data yielded EOPT values of $3.50( \pm 0.05) \mathrm{eV}$ (indirect) and $3.86( \pm$ 0.05) $\mathrm{eV}$ (direct) (Figure S3). These results verify that $\mathrm{CuO}$ and $\mathrm{NH}_{4} \mathrm{SCN}$ can indeed be utilized as novel precursors for the synthesis of $\mathrm{CuSCN}$ layers from solution phase. Interestingly, one may also argue that the conductivity of the resulting material could, in principle, be controlled 
by varying the stoichiometric ratio of the two precursors to generate an excess of $\mathrm{Cu}$ or $\mathrm{SCN}$ in the semiconductor lattice. ${ }^{[49]}$ However, the latter study is beyond the scope of this work.

\section{Surface Morphology of CuSCN Layers Processed From Aqueous Ammonia}

$\mathrm{CuSCN}$ layers were spin-cast on glass substrates identical to those used for top-gate transistor fabrication, as well as on indium-tin-oxide (ITO) coated glass substrates -the transparent anode electrode widely used in solar cell fabrication-and studied via atomic force microscopy (AFM). Figure 2a-h show the surface topography data from eight samples measured with a scan area of $1 \mu \mathrm{m}^{2}$. All CuSCN layers were prepared employing the same conditions used to fabricate the optimized transistors and solar cells which will be discussed in Sections $\mathbf{7}$ and $\mathbf{8}$. The surface topography of plain glass (Figure 2a), glass/ITO (Figure 2e), and PEDOT:PSS (Figure 2f) spin cast onto glass/ITO (glass/ITO/PEDOT:PSS), are also shown for comparison. Layers processed from $\mathrm{CuSCN} / \mathrm{NH}_{3}(\mathrm{aq})$ solutions appear continuous and nanocrystalline (Figure 2bc, and 2g) with remarkably different surface morphology to layers processed from DES (Figure 2d, and 2h). The latter films (CuSCN/DES) contain elongated crystallites of 50-80 nm in length, while the former $\left(\mathrm{CuSCN} / \mathrm{NH}_{3}(\mathrm{aq})\right)$ are composed of considerably smaller spherical grains. Using higher magnification $\left(0.5 \mu \mathrm{m}^{2}\right)$ AFM scans the size of the grains for the $\mathrm{CuSCN} / \mathrm{NH}_{3}(\mathrm{aq})$ layers could also be evaluated, yielding a diameter of 20-30 nm for films processed from a 10 $\mathrm{mg} \mathrm{ml}^{-1}$ solution at $800 \mathrm{rpm}$ (conditions used for TFT fabrication), and 10-20 nm for films spincast from a $15 \mathrm{mg} \mathrm{ml}^{-1}$ solution at $2000 \mathrm{rpm}$ (conditions used in HTL deposition for solar cell fabrication).

Figure 2i shows the surface height histograms extracted from the topography AFM images for CuSCN layers deposited on glass (Figure 2a-d). CuSCN layers processed from $\mathrm{CuSCN} / \mathrm{NH}_{3}$ (aq) solution (Figure 2b) exhibit the smoothest surface topography leading to an 
exceptionally low surface root mean squared (RMS) roughness of $\sim 0.4 \mathrm{~nm}$ (red curve, Figure 2i). On the contrary, CuSCN layers processed from DES show large height variation (pink curve, Figure 2i) resulting in significantly higher surface RMS roughness $(6.4-7.8 \mathrm{~nm})$. Topographical height distributions were also used to determine the degree of surface planarization achieved when $\mathrm{CuSCN} / \mathrm{NH}_{3}(\mathrm{aq})$ solutions were spin-cast onto ITO electrodes. Figure $\mathbf{2} \mathbf{j}$ shows the height distributions extracted from the AFM data in Figure $\mathbf{2 e}-\mathbf{h}$. As can be seen, the layers deposited from the $\mathrm{CuSCN} / \mathrm{NH}_{3}(\mathrm{aq})$ solution exhibit considerably lower surface roughness $(\mathrm{RMS} \sim 1.5 \mathrm{~nm})$ relative to the DES-processed film (RMS $\sim 8.5 \mathrm{~nm})$. This is an important finding as it demonstrates that $\mathrm{CuSCN}$ layers processed from $\mathrm{CuSCN} / \mathrm{NH}_{3}(\mathrm{aq})$ are both continuous and help to planarize the rough ITO surface (RMS $\sim 3.2 \mathrm{~nm}$ ). The latter feature may help to reduce the concentration of interfacial defects which could be highly advantageous for the reliable manufacturing of photovoltaic devices. ${ }^{[50,51]}$ Remarkably, the planarization of ITO by the $\mathrm{CuSCN} / \mathrm{NH}_{3}(\mathrm{aq})$ processed layer appears to be even superior to PEDOT:PSS, which yields surfaces roughness of $\sim 2.6 \mathrm{~nm}$ (red curve, Figure $2 \mathbf{j}$ ).

Since the solubility of $\mathrm{CuSCN}$ in $\mathrm{NH}_{3}$ (aq) at room temperature is relatively low, it was possible to spin-cast and thermally anneal (intermittent thermal annealing at $100{ }^{\circ} \mathrm{C}$ in air) several layers of CuSCN. This simple approach allowed for careful control of the HTL thickness without affecting the structural quality of the resulting layer. Specifically, AFM data (Figure S4) indicate that the multilayer CuSCN HTLs exhibited very similar surface morphology to that measured for single layer systems. Interestingly, a small reduction in the RMS surface roughness of the CuSCN HTL from $1.59 \mathrm{~nm}$, measured for the single layer, to $1.53 \mathrm{~nm}$, for the 3-layer film, was observed (Figure S4), further highlighting the applicability of this simple deposition approach.

CuSCN layers processed from DES solutions were consistently found to be substantially thicker than those processed from $\mathrm{NH}_{3}(\mathrm{aq})$ due to the increased viscosity and slower evaporation rate. The exceptionally smooth CuSCN films spin-cast on glass at $2000 \mathrm{rpm}$ from 
$15 \mathrm{mg} \mathrm{ml}^{-1} \mathrm{NH}_{3}$ (aq) solutions were typically 3-5 nm thick, with triple-spin cast layers exhibiting a thickness of $\sim 10 \mathrm{~nm}$. It is thus remarkable to observe the significant planarization effect that such thin layers of CuSCN have on the surface topography of ITO upon deposition (Figure $\mathbf{2 j}$ ). On the contrary, CuSCN layers processed from DES appear to be significantly thicker and in the range of 30-40 nm-thick in agreement with published results. ${ }^{[6-7]}$ Previous reports on the structure of solid CuSCN suggest that nanocrystalline $\mathrm{CuSCN}$ films typically contain a mixture of the orthorhombic $\alpha$-phase and the hexagonal/rhombohedral $\beta$-phase when deposited from dipropyl sulfide. ${ }^{[2,6]}$ Hence, we note that there is scope to conduct further structural analysis of $\mathrm{CuSCN}$ layers to determine whether the use of aqueous ammonia route has an impact on crystalline phase and orientation, particularly when depositing ultra-thin $\mathrm{CuSCN}$ layers onto highly crystalline anode material such as ITO. Preliminary attempts to analyse the microstructure of the CuSCN layers have been unsuccessful primarily due to the ultra-thin nature of the layers.

The ability to reliably deposit continuous CuSCN layers from DES was also investigated. Figure S5 shows the AFM images for two CuSCN layers deposited using identical conditions, i.e. via spin coating on glass substrates at $800 \mathrm{rpm}$ from $10 \mathrm{mg} \mathrm{ml}^{-1}$ DES solutions, followed by thermal annealing at $100{ }^{\circ} \mathrm{C}$ in air. Evidently, $\mathrm{CuSCN}$ layers, which have been processed following identical experimental conditions, exhibit considerable variations with some films dominated by spherical grains (Figure S5a) and others composed of larger, elongated "rice-like" grains (Figure S5b). CuSCN/DES films spin-cast in ambient air also exhibit a significantly different crystalline structure to films spin-cast in a nitrogen atmosphere (Figure 2d). While further work is needed to identify the mechanisms underpinning these structural variations, similar observations have been reported in the literature for other inorganic materials, such as copper oxide and ITO, where the atmospheric dependence of thin-film morphology is primarily attributed to the presence of gaseous species that contribute to competing chemical reactions during thermal annealing. ${ }^{[52,53]}$ On the contrary, the surface 
morphology of $\mathrm{CuSCN} / \mathrm{NH}_{3}$ (aq) layers spin-cast on glass and annealed at $100{ }^{\circ} \mathrm{C}$ in ambient air demonstrated high reproducibility. This remarkable feature combined with the elimination of the sulphur-based solvent makes the proposed $\mathrm{CuSCN} / \mathrm{NH}_{3}(\mathrm{aq})$ deposition approach a highly promising technology for the growth of HTLs for a wide range of emerging applications.

The deposition and in-situ synthesis of $\mathrm{CuSCN}$ layers on glass employing a formulation consisting of $\mathrm{CuO}$ and $\mathrm{NH}_{4} \mathrm{SCN}$ powders dissolved in $\mathrm{NH} 3(\mathrm{aq})$, was also investigated. Figure S6 shows the topography AFM image of the resulting layer after it has been thermally annealed in air. The layers are characterized by a similar surface morphology to those deposited via the $\mathrm{CuSCN} / \mathrm{NH}_{3}(\mathrm{aq})$ formulation and contain spherical grains with a diameter in the range 20-30 $\mathrm{nm}$. The surface RMS roughness of the layers is low $(\sim 0.6 \mathrm{~nm})$ and comparable to that of those deposited using the $\mathrm{CuSCN} / \mathrm{NH}_{3}(\mathrm{aq})$ formulation. Most importantly, the resulting $\mathrm{CuSCN}$ films exhibit absorption characteristics identical to layers processed from CuSCN/DES and $\mathrm{CuSCN} / \mathrm{NH}_{3}(\mathrm{aq})$ solutions (Figure S2), further verifying the successful formation of CuSCN.

\section{Density-Functional Theory Calculations}

In order to probe the electronic properties of $\mathrm{CuSCN}$ we performed Density-Functional Theory (DFT) calculations with the code Quantum Espresso. ${ }^{[54]}$ The details and parameters of the calculations are the same as those used previously for CuSCN. ${ }^{[49,55,56]}$ The DFT values for the lattice vector and energetics of $\mathrm{CuSCN}$ are in close agreement with pertinent experimental findings. In particular, the calculations ${ }^{[49]}$ show that the wurtzite phase of bulk CuSCN (the socalled beta phase) is the most stable CuSCN polymorph, as observed. Moreover, the difference between $\mathrm{DFT}^{[49]}$ and experimental structural parameters (namely, lattice parameters and atom coordinates within the unit cell of beta-CuSCN) is $<1 \%$, which confirms that DFT calculations provide an accurate description of the properties of wurtzite $\mathrm{CuSCN}$.

In this work, we extended the scope of the DFT calculations and also obtained the socalled partial (or projected) densities of states (PDOS). The PDOS results can be combined with 
XPS spectra to provide insight into the character of the electronic states within the valence band of the material. In this respect, PDOS plots show that the valence band of $\mathrm{CuSCN}$ is dominated by $\mathrm{Cu}$-related states, whereas the conduction band shows significant contributions from the SCN groups, in agreement with other DFT studies. ${ }^{[1]}$ More details on the fine structure of PDOS and related XPS spectra are given in the following section.

\section{Elemental Composition, Chemical Bonding and Density of States by XPS}

The chemical and electronic properties of CuSCN layers processed from CuSCN/DES and $\mathrm{CuSCN} / \mathrm{NH}_{3}$ were investigated using XPS. Survey spectra of both samples show all expected core levels as well as a small contribution from the silicon (Si) substrate (Figure S7). Core level spectra collected for the CuSCN layers processed from DES (Figure S8) and $\mathrm{NH}_{3}$ (aq) (Figure S9) solutions were analysed in order to investigate the chemical environments present on the layer surfaces. All binding energy (BE) positions stated in the following discussion are those of $\mathrm{CuSCN} / \mathrm{DES}$. Values for layers processed from $\mathrm{CuSCN} / \mathrm{NH}_{3}(\mathrm{aq})$ differ only slightly and are within the uncertainty associated with the measurement (see Table S1). In both cases the main $\mathrm{Cu} 2 p$ core line is at a $\mathrm{BE}$ of $932.6 \mathrm{eV}$, which can be assigned to $\mathrm{Cu}^{1+}$ in $\mathrm{CuSCN}$. A slight asymmetry (represented by an additional feature denoted with an asterisk in Figures $\mathbf{S 8}$ and S9) is observed for both samples. The absence of satellite features for the CuSCN/DES film, which are typical for $\mathrm{Cu}$ in the $2+$ oxidation state, excludes this asymmetry stemming from $\mathrm{Cu}^{2+}$ species (Figure S10), in agreement with previous reports. ${ }^{[57]}$ Furthermore, asymmetry due to the presence of either $\mathrm{CuO}$ or $\mathrm{Cu}_{2} \mathrm{O}$ can be excluded, as the $\mathrm{O} 1 \mathrm{~s}$ core level for both samples does not show any features corresponding to these compounds (Figure S11), which would appear at BEs of 529.6 and $530.5 \mathrm{eV}$, respectively. ${ }^{[58]}$ The film deposited from $\mathrm{CuSCN} / \mathrm{NH}_{3}(\mathrm{aq})$ solution shows a further peak at $934.9 \mathrm{eV}$, which is attributed to the presence of $\mathrm{CuSO}_{4}{ }^{\left[{ }^{[5]}\right.}$ This is further confirmed by a strong signal from $\mathrm{S}-\mathrm{O}$ environments in both the $\mathrm{O} 1 \mathrm{~s}$ core level at 
$531.9 \mathrm{eV}$ and the $\mathrm{S} 2 p$ core level at $168.8 \mathrm{eV} \cdot{ }^{[60]} \mathrm{In}$ comparison, this feature is very small in the S $2 p$ spectrum of the DES deposited film. Besides the main peak in the S $2 p$ core level at 163.4 $\mathrm{eV}$, which corresponds to $\mathrm{CuSCN}$, an additional small contribution at lower BE $(162.6 \mathrm{eV})$ is found, which could stem from either $\mathrm{C}-\mathrm{S}$ or $\mathrm{Cu}-\mathrm{S}$ environments. ${ }^{[61]}$ The $\mathrm{C} 1 s$ core levels for both samples are dominated by a peak at $286.0 \mathrm{eV}$, corresponding to $\mathrm{CuSCN}$, and show further peaks at $285.0 \mathrm{eV}$ and $290.1 \mathrm{eV}$ attributed to adventitious carbon and O-C-N (e.g. similar to biuret) environments, respectively. The sample deposited from DES solutions shows a further peak at a low BE of $284.5 \mathrm{eV}$ most likely stemming from C-S environments. Finally, the N $1 s$ core level shows the main $\mathrm{CuSCN}$ peak at $398.5 \mathrm{eV}$ with both samples also exhibiting a feature at $399.8 \mathrm{eV}$ assigned to $\mathrm{N}-\mathrm{H}$ environments. The $\mathrm{NH}_{3}(\mathrm{aq})$ processed $\mathrm{CuSCN}$ layer has a further low intensity peak at $399.1 \mathrm{eV}$ assigned to a minor contribution from C-N environments. Quantitative analysis of the peak fits was used to investigate the elemental ratios present in CuSCN, which are summarized in Table S2. Only peaks attributed to CuSCN (marked with an asterisk in Table S1) were used for the quantification. Within the accuracy of the quantification $( \pm 0.5 \%)$ the $\mathrm{S}: \mathrm{C}: \mathrm{N}$ ratios are $1: 1: 1$. An excess of $\mathrm{Cu}$ on the surface compared to $\mathrm{CuSCN}$ is found, in particular for the $\mathrm{CuSCN} / \mathrm{NH}_{3}(\mathrm{aq})$ processed sample, which is most likely due to the overlap of $\mathrm{Cu} 2 p$ signals from different $\mathrm{Cu}^{1+}$ environments as observed in the $\mathrm{S}, \mathrm{C}$, and $\mathrm{N}$ core levels, which cannot be resolved in XPS due to negligible chemical shifts.

In addition to core level spectra, the valence band (VB) spectra of both samples were collected using XPS (Figure 3). A clear shift of the VB maximum VB $\mathrm{VBx}_{\max }$ to higher BE relative to the Fermi energy $\left(\mathrm{E}_{\mathrm{F}}\right)$ is visible in the $\mathrm{CuSCN} / \mathrm{NH}_{3}(\mathrm{aq})$ processed layers (Figure 3a). From linear fits to the VB onset the separation was found to be $0.8 \mathrm{eV}$ for CuSCN/DES and $1.2 \mathrm{eV}$ for films processed from $\mathrm{CuSCN} / \mathrm{NH}_{3}(\mathrm{aq})$. In order to analyse the orbital contributions to the valence bands, experimental data were compared to theoretical calculations based on results discussed in Section 4. To take into account experimental considerations, theoretically derived partial densities of states (PDOS) of $\mathrm{CuSCN}$ were corrected using one electron atomic cross 
sections from Yeh and Lindau ${ }^{[62]}$ to account for differences in signal intensities. A Gaussian broadening of $300 \mathrm{meV}$ was applied, comparable to the minimum experimental broadening at $\mathrm{E}_{\mathrm{F}}$ (Figure S12). The total DOS resulting from the present calculations can then be directly compared to the spectroscopy results, with both experimental and theoretical results aligned to the position of the main $\mathrm{Cu} 3 d$ peak of $\mathrm{CuSCN} / \mathrm{DES}$. One previous account of a valence band spectrum of CuSCN measured by XPS and compared to calculated DOS exists, however, the energy resolution of these measurements did not allow for an in depth analysis of the VB features and the assignment of related contributions. ${ }^{[1]}$ Excellent agreement is found between experiment and theory, in particular concerning the number of features and their energy positions (Figure 3b). Five major contributions to the VB can be identified. The first feature located between 2 and $4 \mathrm{eV}$ is dominated by $\mathrm{Cu} 3 d$ states with some mixing from $\mathrm{Cu} 3 p$ and $\mathrm{S}$ $3 p$ states at the very top of the VB. The second feature $(4-6 \mathrm{eV})$ is also dominated by $\mathrm{Cu} 3 d$ states but the influence of both $\mathrm{Cu} 3 p$ and $\mathrm{S} 3 p$ states is increasing. The third feature $(6-8 \mathrm{eV})$ is dominated by $\mathrm{Cu} 3 p$ mixed with $\mathrm{S} 3 p$ states, while the fourth $(8-9 \mathrm{eV})$ and fifth $(9-11 \mathrm{eV})$ features show an additional contribution from $\mathrm{N} 2 s$ states. C states contribute a non-significant amount to the valence states with only a small contribution of $\mathrm{C} 2 s$ states found in the fifth feature. Comparatively, the relative intensities of the second and third features are enhanced in the $\mathrm{CuSCN} / \mathrm{NH}_{3}(\mathrm{aq})$ sample.

\section{Environmental Stability of CuSCN Layers}

Air photoemission spectroscopy (APS) and Kelvin probe (KP) techniques were used to further study the electronic energy levels of CuSCN. The APS spectra obtained from CuSCN layers processed from $\mathrm{CuSCN} / \mathrm{NH}_{3}(\mathrm{aq})$ and DES on ITO-coated glass substrates were analysed to extract the valence band maximum $\left(\mathrm{VB}_{\max }\right)$ energy. Obtained results indicated that $\mathrm{VB}_{\max }$ is independent of the solvent used to within $\pm 0.05 \mathrm{eV}$, an error attributed to the measurement 
resolution. By measuring sets of three $\mathrm{CuSCN}$ samples deposited from $\mathrm{NH}_{3}(\mathrm{aq})$ and $\mathrm{DES}$, the $\mathrm{VB}_{\max }$ energy of CuSCN was found to be $-5.36( \pm 0.05)$ and $-5.40( \pm 0.05) \mathrm{eV}$. The APS data further confirms that $\mathrm{CuSCN}$ is chemically stable even when processed in environments with high oxygen and water content. On the basis of these findings, we conclude that the material is compatible with the aqueous synthetic/deposition route proposed.

Next, the environmental stability of CuSCN HTLs was examined using the KP system by monitoring temporal variations in the Fermi energy level following exposure to ambient air. At time $(\mathrm{t})=0 \mathrm{~s}$, which corresponds to the time when the sample was transferred from the fabrication environment to the sample chamber, $\mathrm{E}_{\mathrm{F}}$ for $\mathrm{NH}_{3}(\mathrm{aq})$ and DES-processed CuSCN layers were 5.07 and $5.23 \mathrm{eV}$, respectively. Notably, the value of $\mathrm{E}_{\mathrm{F}}$ for both samples was found to increase as compared to that recorded at $\mathrm{t}=0 \mathrm{~s}$ following 1 hour of ambient air exposure, reaching values of $5.15 \mathrm{eV}\left(\mathrm{NH}_{3}(\mathrm{aq})\right)$ and $5.39 \mathrm{eV}(\mathrm{DES})$. This characteristic energy shift towards the $\mathrm{VB}_{\max }$ was attributed to atmospheric p-doping. ${ }^{[6]}$ However, as discussed previously in Section 5, the high resolution valence band spectra indicated that the $\mathrm{E}_{\mathrm{F}}$ is $\sim 0.8 \mathrm{eV}$ above the $\mathrm{VB}_{\max }$ in $\mathrm{CuSCN}$ layers processed from DES, and $\sim 1.2 \mathrm{eV}$ above the $\mathrm{VB}_{\max }$ in $\mathrm{CuSCN}$ layers processed from $\mathrm{NH}_{3}(\mathrm{aq})$ solutions. To this end, the high vacuum environment used during XPS measurements would most likely lead to oxygen and water desorption and as such yield a more realistic $\mathrm{E}_{\mathrm{F}}$. Therefore, the smaller energy difference determined from the KP and APS data is attributed to a reversible and unintentional $p$-doping of $\mathrm{CuSCN}$ that arises from sample exposure to ambient air prior to and during measurements. Encouragingly, no change in the $\mathrm{VB}_{\max }$ energy of CuSCN layers, evaluated by APS, was observed following a 7-day period of ambient air exposure. This result verifies the chemical stability of $\mathrm{CuSCN}$ and highlights its potential as a HTL material.

\section{CuSCN Transistors Processed from Aqueous Ammonia Solutions}


The charge transport properties of $\mathrm{CuSCN}$ layers processed from $\mathrm{NH}_{3}(\mathrm{aq})$ and $\mathrm{DES}$ were investigated in top-gate, bottom-contact (TG-BC) transistors using poly(vinylidenefluoridetrifluoroethylene-chlorofluoroethylene) $[\mathrm{P}(\mathrm{VDF}-\mathrm{TrFE}-\mathrm{CFE})]$ as the high-k polymer dielectric (Figure 4, inset). The transfer characteristics (i.e. source-drain current $\left(\mathrm{I}_{\mathrm{D}}\right)$ versus gate voltage $\left(\mathrm{V}_{\mathrm{G}}\right)$ of the transistors were recorded at two drain voltages $\left(\mathrm{V}_{\mathrm{D}}\right)$ corresponding to the linear (lin) and saturation (sat) operating regimes. Electrical characterization of the transistors was carried out in a nitrogen-filled glovebox to avoid unwanted exposure of the CuSCN layers to atmospheric oxidants. Figure 4 shows the transfer curves measured in saturation for two CuSCN transistors, one processed from $\mathrm{NH}_{3}(\mathrm{aq})$ and one from DES, for comparison. The output characteristics and the linear regime transfer curves corresponding to the device data in Figure 4 are presented in Figure S13 in Supporting Information. The channel length (L) and width (W) for both transistors were 30 and $1000 \mu \mathrm{m}$, respectively. Both transistors exhibit clear holetransporting characteristics with low operating voltages $(\sim|10| \mathrm{V})$, small hysteresis and clear channel current saturation. Encouragingly, $\mathrm{CuSCN}$ layers processed from $\mathrm{NH}_{3}(\mathrm{aq})$ exhibit improved hole transport as compared to DES-processed layers, manifested as increased channel current (Figure 4). Analysis of the data obtained from the $\mathrm{NH}_{3}(\mathrm{aq})$-processed CuSCN devices yielded a mean and a maximum hole mobility of 0.05 and $0.07 \mathrm{~cm}^{2} \mathrm{~V}^{-1} \mathrm{~s}^{-1}$, respectively. A comparatively lower mean saturation mobility of $0.01 \mathrm{~cm}^{2} \mathrm{~V}^{-1} \mathrm{~s}^{-1}$ was extracted for the DESprocessed CuSCN transistors (Table 1).

The subthreshold swing (SS) was also calculated from the linear transfer characteristics for each $\mathrm{CuSCN}$ transistor and used to extract the corresponding trap concentrations. ${ }^{[63]}$ Surprisingly, and despite the improved hole transport observed in $\mathrm{NH}_{3}(\mathrm{aq})$-processed CuSCN TFTs, the SS values obtained were approximately $1 \mathrm{~V} \mathrm{dec}^{-1}$ higher than those extracted from devices processed from DES (typically 1-2 $\mathrm{V} \operatorname{dec}^{-1}$ ). Corresponding analysis yields trap concentration in the range of $4.2-6.3 \times 10^{13} \mathrm{~cm}^{-2}$ for $\mathrm{CuSCN}$ devices processed from $\mathrm{NH}_{3}(\mathrm{aq})$, as compared to $2.1-4.2 \times 10^{13} \mathrm{~cm}^{-2}$ for DES-processed transistors. These finding highlights the 
potential for further device optimization through interfacial engineering. Finally, functional $\mathrm{CuSCN}$ transistors were also realized from $\mathrm{CuO} / \mathrm{NH}_{4} \mathrm{SCN}$ precursor solution (Figure S14). Although the resulting devices exhibited significantly lower hole mobility $\left(\sim 0.002 \mathrm{~cm}^{2} \mathrm{~V}^{-1} \mathrm{~s}^{-1}\right)$, we note that process optimization is anticipated to lead to performance improvement. Nevertheless, the result demonstrates the generic nature of the synthetic route proposed here for the growth of $\mathrm{CuSCN}$ at low temperature.

\section{Organic and Organometal Halide Perovskite Photovoltaic Cells with CuSCN Hole- Transport Layers Processed from Aqueous Solutions in Air}

Finally, the suitability of $\mathrm{NH}_{3}(\mathrm{aq})$-processed $\mathrm{CuSCN}$ for application as HTLs in organic bulkheterojunction $(\mathrm{BHJ})$ and organometal halide perovskite solar cells was investigated. First, normal architecture single-stack organic photovoltaic (OPV) devices were fabricated using poly[4,8-bis(5-(2-ethylhexyl)thiophen-2-yl)benzo[1,2-b:4,5-b']dithiophene-alt-3fluorothieno[3,4-b]thiophene-2-carboxylate] $(\mathrm{PTB} 7-\mathrm{Th})$ as the donor and $[6,6]-$ phenyl-C 71 butyric acid methyl ester $\left(\mathrm{PC}_{70} \mathrm{BM}\right)$ as the acceptor material (Figure 5a) materials. Figures $\mathbf{5 b}$ and $\mathbf{5 c}$ show the standard device architecture employed and the corresponding material energetics, respectively. For this type of cell, bathocuproine (BCP) was employed as the electron transport layer (ETL) and was deposited via thermal sublimation. Figure 5d displays the current density-voltage $(\mathrm{J}-\mathrm{V})$ characteristics of three identical solar cells that differ only by the type of the HTL employed, namely; CuSCN/NH $3(a q), C u S C N / D E S$, and PEDOT:PSS. The extracted cell parameters are summarized in Table 2. Evidently, devices based on $\mathrm{CuSCN} / \mathrm{NH}_{3}(\mathrm{aq})$ demonstrate enhanced performance with respect to cells made with PEDOT:PSS and CuSCN/DES HTLs. Notably, compared to PEDOT:PSS the bilayer $\mathrm{CuSCN} / \mathrm{NH}_{3}(\mathrm{aq})$-containing OPV cells yield higher short circuit current $\left(\mathrm{J}_{\mathrm{SC}}\right)$, open circuit voltage $\left(\mathrm{V}_{\mathrm{OC}}\right)$ and fill factor $(\mathrm{FF})$, resulting in cells with an average power conversion 
efficiency (PCE) of 10.01\% (measured over eight devices) and a maximum value of $10.7 \%$. Remarkably, the latter PCE value is higher than those measured for the best-performing inverted cell $(\mathrm{PCE}=10.2 \%)$ prepared from the same active layer (see Figure 5e). The PCE value of $10.7 \%$ represents one of the highest, if not the highest, values achieved to date in non-inverted PTB7-Th:PC 70 BM-based OPVs. Furthermore, and as evident from Table 2, $\mathrm{CuSCN} / \mathrm{NH}_{3}$ (aq) HTLs processed via single, double and triple spin-coating steps all yield OPVs with average PCE values (>9.25\%) above that of PEDOT:PSS (9.1\%) clearly demonstrating the ability to realize high-performance OPVs using CuSCN HTLs processed from an aqueous solution in air.

Previous reports have attributed the superior performance of OPVs with CuSCN HTLs, as compared to PEDOT:PSS, to a combination of an increase in Voc due to the deeper $\mathrm{VB}_{\mathrm{MAX}}$ energy of $\mathrm{CuSCN},{ }^{[7,10]}$ and an enhanced $\mathrm{J}_{\mathrm{SC}}$ due to decreased parasitic absorption by the HTL. ${ }^{[7,8]}$ Additionally, the low electron affinity of $\mathrm{CuSCN}(-1.5 \mathrm{eV}$, see Figure 5c) suppresses the dark minority carrier injection from the anode to the active layer (and vice versa), which is manifested as reduced reverse dark saturation current when compared to PEDOT:PSS-based cells (Figure 5f). Furthermore, the ultra-smooth surface of the $\mathrm{CuSCN} / \mathrm{NH}_{3}(\mathrm{aq})$ HTLs (Figure $\mathbf{2 g}$ and $\mathbf{2 j}$ ) is believed to lead to improved electrical contact with the active layer, which in turn translates to a notable increase in the FF from 0.60 for PEDOT:PSS-based cells to 0.63 for $\mathrm{CuSCN} / \mathrm{NH}_{3}(\mathrm{aq})$-based cells. Conversely, the FF for cells with CuSCN/DES HTLs is found to be lower than that for PEDOT:PSS-containing OPVs (Table 2). We attribute this to the high surface roughness of CuSCN/DES layers (Figure $\mathbf{2 h}$ and $\mathbf{2 j}$ ), which could well lead to a poor interfacial contact between $\mathrm{CuSCN}$ and the PTB7-Th: $\mathrm{PC}_{70} \mathrm{BM}$ blend, with adverse effects on the charge extraction efficiency.

The effect of $\mathrm{CuSCN} / \mathrm{NH}_{3}(\mathrm{aq})$ on the operating stability of the OPV cells was also briefly investigated. Standard architecture PTB7-Th:PC 70 BM-based cells based on 
PEDOT:PSS HTLs are known to suffer from rapid performance degradation due to the inability of PEDOT:PSS to filter UV radiation, which has been shown to lead to the degradation of the active layer due to morphological changes. ${ }^{[64,65]}$ Figure $\mathbf{5 g}$ shows the preliminary stability data for two PTB7-Th:PC ${ }_{70} \mathrm{BM}$ based OPV cells with PEDOT:PSS (solid symbols) and $\mathrm{CuSCN} / \mathrm{NH}_{3}(\mathrm{aq})$ (open symbols) as the HTL. Cells with PEDOT:PSS show a $35 \%$ drop in the PCE following a 10 minute exposure to constant AM1.5 illumination. In contrast, cells made with $\mathrm{CuSCN} / \mathrm{NH}_{3}(\mathrm{aq})$ undergo only a $15 \%$ drop in PCE for the same illumination period, which is primarily attributed to the FF remaining almost unaffected by illumination in the devices containing CuSCN/NH 3 (aq) HTLs (Figure 5g), and is due to the strong UV filtering property of $\mathrm{CuSCN}$ as evident from the UV absorption peak in Figure 1b. Although preliminary, the results indicate that OPVs with $\mathrm{NH}_{3}(\mathrm{aq})$-processed $\mathrm{CuSCN}$ HTLs could potentially outperform those based on commercially available HTL material technologies.

Finally, the applicability of the aqueous-processed CuSCN $\mathrm{HTLs}^{[66,67]}$ to organometal halide perovskite photovoltaic cells ${ }^{[68-71]}$ was also investigated. The perovskite precursor solution was prepared using a solvent blend of dimethyl sulfoxide and gamma butyrolactone, which is a less hazardous alternative to some precursor solvents, such as N,Ndimethylformamide, reported in the literature. ${ }^{[72]}$ Figure $6 \mathbf{a}-\mathbf{b}$ shows the device architecture and the corresponding material energetics, while Figure 6c displays the J-V characteristics obtained using a $50 \mathrm{mV} / \mathrm{s}$ scanning rate, for the optimized organometal halide perovskite solar cells with CuSCN/NH 3 (aq) and PEDOT:PSS as HTLs. The PCE for the PEDOT:PSSbased cell is $13.6 \%$, a reasonable value compared with literature using similar methods. ${ }^{[73]}$ Replacing PEDOT:PSS with $\mathrm{CuSCN} / \mathrm{NH}_{3}(\mathrm{aq})$ as $\mathrm{HTL}$, however, results in a significant increase of PCE to $17.5 \%$. The performance enhancement is attributed to two main effects. Firstly, to a $\mathrm{V}_{\mathrm{OC}}$ increase by $200 \mathrm{mV}$ from $0.9 \mathrm{~V}$ for PEDOT:PSS to $1.1 \mathrm{~V}$ for $\mathrm{CuSCN} / \mathrm{NH}_{3}(\mathrm{aq})$, which indicates improved energetic alignment between the HTL and 
$\mathrm{CH}_{3} \mathrm{NH}_{3} \mathrm{PbI}_{3}$ (Figure 6b), and secondly to an increased $\mathrm{J}_{\mathrm{SC}}\left(22.7 \mathrm{~mA} / \mathrm{cm}^{2}\right)$. However, we note that this improvement is accompanied by a slight drop in the FF from 0.73 for PEDOT:PSS, to 0.71 for the $\mathrm{CuSCN} / \mathrm{NH}_{3}$ (aq)-based cells. Generally speaking, the relatively low $\mathrm{V}_{\mathrm{OC}}$ represents the major hurdle for achieving high PCE in planar inverted perovskite cells (HTL on bottom, ETL on top), particularly using PEDOT:PSS as the HTL. It is therefore notable that the $\mathrm{V}$ OC value of $1.1 \mathrm{~V}$ achieved here for the $\mathrm{CuSCN} / \mathrm{NH}_{3}(\mathrm{aq})$-based perovskite cells is comparable to values achieved in some highly efficient invert-structured cells using poly(triaryl amine) (PTAA) or nickel oxide $\left(\mathrm{NiO}_{\mathrm{x}}\right)$ as HTLs. ${ }^{[74,75]}$ In contrast, replacing PEDOT:PSS with CuSCN/DES as HTL resulted in a significantly lower maximum PCE of $10.2 \%$. The $\mathrm{J}-\mathrm{V}$ characteristics of a $\mathrm{CH}_{3} \mathrm{NH}_{3} \mathrm{PbI}_{3}$ solar cell based on a CuSCN/DES HTL is presented in Figure S15 in Supporting Information. We note that this experiment was conducted at a later date, where the best PEDOT:PSS-based reference cell yielded a PCE of 13.9\%. The inferior performance of the CuSCN/DES-based devices is attributed to nonuniformities in the HTL morphology, which is likely to have a significant negative impact on the perovskite crystallization process, and result in increased shunting pathways and interfacial current losses. This is indicated by the lower FF (0.63-0.71) and $\mathrm{J}_{\mathrm{SC}}\left(10.5-14.2 \mathrm{~mA} \mathrm{~cm}{ }^{-2}\right)$ observed in cells containing CuSCN/DES HTLs.

Furthermore, Figure S16 (Supporting Information) shows that solar cells based on $\mathrm{CuSCN} / \mathrm{NH}_{3}$ (aq) HTLs exhibit better operating stability over a 3 h period of constant 1 -sun simulated solar illumination compared to identical devices containing PEDOT:PSS and $\mathrm{CuSCN} / \mathrm{DES}$ HTLs. In this preliminary test, PCE of the $\mathrm{CuSCN} / \mathrm{NH}_{3}(\mathrm{aq})$-based cell dropped to $99.5 \%$ of its original value during the first $1 \mathrm{hr}$ of illumination, and decreased steadily to $91.1 \%$ of the initial efficiency after $2 \mathrm{~h}$. Meanwhile, PCE of the PEDOT:PSS-based device fluctuated over time and decreased to $91.0 \%$ of its original value over the $3 \mathrm{~h}$ period, and PCE of the CuSCN/DES-based device deteriorated rapidly to $82.7 \%$ of its original value during the same time period. The poor operating stability of the CuSCN/DES -based solar 
cell in a nitrogen atmosphere supports our hypothesis about the crystallization of $\mathrm{CH}_{3} \mathrm{NH}_{3} \mathrm{PbI}_{3}$ on $\mathrm{CuSCN} / \mathrm{DES}$, because the formation of a disordered and defective HTLperovskite interface is likely to be a major cause of cell instability. Further research is needed to experimentally determine the physical mechanisms that underpin these differences in operating stability, but that is beyond the scope of this work. Importantly, while the use of aqueous ammonia may raise concerns about residual water traces existing in the HTL film, the superior performance and stability of solar cells containing $\mathrm{CuSCN} / \mathrm{NH}_{3}(\mathrm{aq}) \mathrm{HTLs}$ reveal no evidence of the aqueous processing solvent having a detrimental effect on the perovskite layer formation or device function. Therefore, we conclude that thermally annealing of the as-spun $\mathrm{CuSCN} / \mathrm{NH}_{3}(\mathrm{aq})$ layers at $150{ }^{\circ} \mathrm{C}$ for 15 minutes is sufficient to fully evaporate aqueous ammonia, and obtain an anhydrous HTL that functions extremely well in perovskite solar cells.

\section{Conclusion}

In conclusion, we have demonstrated high performance $p$-channel transistors, organic solar cells and organometal halide perovskite solar cells based on CuSCN hole-transport layers processed from an aqueous ammonia-based precursor solution in ambient air. Various material characterization techniques confirmed that $\mathrm{CuSCN}$ layers processed from $\mathrm{NH}_{3}(\mathrm{aq})$ solutions exhibited high compositional purity, exceptional surface uniformity, and superior substrate planarization properties relative to $\mathrm{CUSCN}$ layers processed from DES as well as PEDOT:PSS. Furthermore, the improved hole mobilities observed in $\mathrm{NH}_{3}(\mathrm{aq})$-processed $\mathrm{CuSCN}$ transistors, as compared to DES-processed devices, indicated that the proposed deposition route yields CuSCN with enhanced hole transport characteristics. Consequently, PTB7-Th:PC $70 \mathrm{BM}$ cells based on $\mathrm{NH}_{3}$-processed CuSCN HTLs exhibit improved PCE $(10.7 \%)$, JSC $\left(21.1 \mathrm{~mA} / \mathrm{cm}^{2}\right)$, FF (0.63) and high $\mathrm{V}_{\mathrm{OC}}(0.80 \mathrm{~V})$ as compared to PEDOT:PSS-based devices. Surprisingly, the 
maximum PCE value of $10.7 \%$ is achieved in cells with non-inverted architecture. Lastly, the applicability of the aqueous-processed CuSCN HTL was extended to organometal halide perovskite photovoltaic cells for which a maximum PCE of $17.5 \%$ was achieved - a remarkably higher value than that achieved in PEDOT:PSS-based cells (13.6\%). These results demonstrate the enormous potential of $\mathrm{CuSCN}$ for a wide range of opto/electronic applications as it can now be solution-processed from an environmentally-friendly aqueous precursor formulation at low temperatures and in atmospheric air without any special precautions.

\section{Experimental Section}

CuSCN Preparation: Solutions were prepared by dissolving CuSCN (99\%, Sigma-Aldrich) in diethyl sulfide (Sigma-Aldrich, 98\%) and aqueous ammonia (50\% v/v, Alfa Aesar) at concentrations of $10 \mathrm{mg} \mathrm{ml}^{-1}, 15 \mathrm{mg} \mathrm{ml}^{-1}$ and $25 \mathrm{mg} \mathrm{ml}^{-1}$. After stirring the solutions at $50{ }^{\circ} \mathrm{C}$ for 1 hour, the solutions were left to stand in a room temperature environment for an additional hour until the system reached thermodynamic equilibrium. $\mathrm{CuSCN} / \mathrm{NH}_{3}$ solutions were filtered using a hydrophilic filter prior to thin-film deposition. In order to study the complexation chemistry of the CuSCN-ammine complex, copper(II) oxide (CuO, 99\%, Sigma-Aldrich) and ammonium thiocyanate $\left(\mathrm{NH}_{4} \mathrm{SCN}, 99 \%\right.$, Sigma-Aldrich) were dissolved at a total concentration of $10 \mathrm{mg} \mathrm{ml}^{-1}(1: 1 \mathrm{molar}$ ratio) in aqueous ammonia. CuSCN solutions were $\mathrm{pH}$ tested prior to ambient air deposition as the literature reports that cyanide compounds are detected in aqueous thiocyanate solutions under acidic conditions, but are not observed under alkaline conditions, particularly when the $\mathrm{pH}$ exceeds $10.6 .^{[76]}$ The organic DES solvent and the $\mathrm{CuSCN} / \mathrm{DES}$ solutions were found to be neutral with a $\mathrm{pH}$ of 7 . In contrast, the aqueous 7.0 M ammonium hydroxide solvent utilized in this experiment was found to be strongly alkaline, with a $\mathrm{pH}$ of 12 . While the dark colour of the $\mathrm{CuSCN} / \mathrm{NH}_{3}(\mathrm{aq})$ solution limited the precision of 
the $\mathrm{pH}$ indicator test, a $\mathrm{pH}$ in the range 11-13 was revealed, confirming the presence of a strong alkaline environment, which tends to inhibit the formation of cyanide compounds. Therefore, the ammonia-based CuSCN solutions were considered suitable for ambient air processing in small volumes. However, further studies to verify these results should be performed prior to proceeding with large-scale production. Notably, in contrast to the $\mathrm{CuSCN}$ solutions, the PEDOT:PSS dispersion is strongly acidic and has a $\mathrm{pH}$ of $1.5-2.5$ as specified by the supplier.

Thin-Film Deposition: Substrates were solvent-cleaned prior to thin-film deposition by a sequential ultrasonication procedure: an aqueous solution of Decon 90, deionized water, acetone, and isopropanol. Next, the samples were dried using a nitrogen flow and UV-ozone treated; the latter step was essential to create a hydrophilic surface for the deposition of $\mathrm{CuSCN}$ from aqueous ammonia. $10 \mathrm{mg} \mathrm{ml}^{-1}, 15 \mathrm{mg} \mathrm{ml}^{-1}$ and $25 \mathrm{mg} \mathrm{ml}^{-1} \mathrm{CuSCN}$ solutions were spincast at room temperature in ambient air or nitrogen atmosphere environments. Higher spin speeds of $2000 \mathrm{rpm}$ and $2500 \mathrm{rpm}$ were used to deposit thin-films of greater uniformity for photovoltaic applications, while a slower spin speed of $800 \mathrm{rpm}$ was utilized to spin-cast thicker films for TFT applications. DES-based CuSCN solutions were spun for $60 \mathrm{~s}$, while the ammonia-based solutions were spun for a shorter time period of $20 \mathrm{~s}$ due to the low boiling point of ammonium hydroxide, typically defined in the literature as $36^{\circ} \mathrm{C}$ for a $30 \% \mathrm{v} / \mathrm{v}$ solution. As-spun films were annealed at $100{ }^{\circ} \mathrm{C}$ for 10 minutes on hotplates in the respective environments. Atmospheric humidity levels were monitored throughout the experiment as 30$40 \%$ in ambient air and $0-5 \mathrm{ppm}$ in the nitrogen-filled glovebox.

Ultraviolet - visible-near-infrared (UV-Vis-NIR) spectroscopy: The samples were measured using a Shimadzu UV-2600 spectrophotometer equipped with an ISR-2600Plus integrating sphere. Transmittance spectra were recorded in the $220-1400 \mathrm{~nm}$ wavelength range, and the absorbance was calculated from the logarithm (base ten) of the spectral data. Liquid samples 
were placed in sealed quartz cuvettes during the measurement procedure, while CuSCN thinfilms were spin-cast at $2000 \mathrm{rpm}$ on solvent-cleaned quartz substrates. Additionally, the reflectance spectra of thin-films were recorded over an identical range of wavelengths in order to determine the optical bandgap of the semiconductor using Tauc analysis. All data were analysed using Origin software.

Atomic force microscopy (AFM): The surface morphology of films spin-cast on glass and ITO was studied using tapping-mode AFM - an Agilent 5500AFM system. The cantilever had an approximate resonant frequency of $270 \mathrm{kHz}$ and a force constant of $40 \mathrm{~N} \mathrm{~m}^{-1}$, and the topography and phase data were recorded using PicoView scanning probe microscopy control software. Information on material crystallinity, grain size, and thin-film uniformity were determined from the analysis of $1 \mu \mathrm{m}^{2}$ and $10 \mu \mathrm{m}^{2} \mathrm{AFM}$ images using Gwyddion software; all surface height data were extracted from AFM images at an identical resolution in order to generate representative distributions.

$X$-ray photoelectron spectroscopy (XPS): The surface of CuSCN films spin-cast on solventcleaned heavily doped $\mathrm{Si}^{++}$substrates was characterized using $\mathrm{X}$-ray photoelectron spectroscopy (XPS). The spectra were recorded on a Thermo Scientific K-Alpha ${ }^{+}$spectrometer operating at a base pressure of $2 \times 10^{-9}$ mbar. This system incorporates a monochromated, microfocused $\mathrm{Al} \mathrm{K} \alpha \mathrm{X}$-ray source $(\mathrm{h} v=1486.6 \mathrm{eV})$ and a $180^{\circ}$ double focusing hemispherical analyser with a 2D detector. The X-ray source was operated at $6 \mathrm{~mA}$ emission current and 12 $\mathrm{kV}$ anode bias. Data were collected at pass energies of $200 \mathrm{eV}$ for survey, $20 \mathrm{eV}$ for core level, and $15 \mathrm{eV}$ for valence band spectra using an X-ray spot size of $400 \mu \mathrm{m}^{2}$. Samples were mounted using carbon loaded conductive tape, and in addition, a flood gun was used to minimize sample charging. All spectra were aligned using the C $1 s$ contribution of adventitious carbon at 285.0 eV. All data were analysed using the Avantage software package. 
Kelvin Probe (KP) measurements and air photoemission spectroscopy (APS): The Fermi level and valence band maximum in $\mathrm{CuSCN}$ films were determined using $\mathrm{KP}$ contact potential difference measurements and APS, respectively. Films were spin-cast on solvent-cleaned ITOcoated glass substrates and full coverage of the conductive ITO was ensured. The KP-APS setup comprised of a KP Technology SKP5050 Scanning Kelvin Probe and an APS02 Air Photoemission System. The contact potential difference of each semiconductor thin-film was measured relative to that of a polished silver reference sample, and hence, the Fermi level was calculated with respect to the work function of the reference metal. The KP measurements were made immediately following the transfer of $\mathrm{CuSCN}$ films from the fabrication environment to the sample chamber of the instrument, and data recording timescales were adjusted accordingly to monitor temporal variations in the Fermi level. The energy corresponding to the valence band edge was extracted from APS data, where each sample was exposed to ultraviolet radiation of wavelengths in the 200-300 $\mathrm{nm}$ range, and the photoemission signal from the layer surface was recorded as a function of wavelength.

Transistor Fabrication and Characterization: Transistors with a staggered top-gate, bottomcontact (TG-BC) architecture were fabricated by spin-casting the $10 \mathrm{mg} \mathrm{ml}^{-1} \mathrm{CuSCN}$ precursor solutions at $800 \mathrm{rpm}$ on glass substrates. $40 \mathrm{~nm}$-thick gold source-drain contacts (S-D) were thermally evaporated using shadow masks, and subsequently, UV-ozone treated to improve hole-injection into the valence band of $\mathrm{CuSCN}^{[6]} \mathrm{Next}, \mathrm{CuSCN}$ films were spin-cast and thermally annealed according to procedures detailed above. The high-k relaxor ferroelectric polymer, poly(vinylidenefluoride-trifluoroethylene-chlorofluoroethylene) $\quad[\mathrm{P}(\mathrm{VDF}-\mathrm{TrFE}-$ CFE)], was spin-cast on $\mathrm{CuSCN}$ as the dielectric and annealed at $60{ }^{\circ} \mathrm{C}$ for 1 hour. Finally, 40 nm-thick aluminium gate electrodes were thermally evaporated using shadow masks in high vacuum to complete the device fabrication. Transistors were characterized at room temperature 
in a nitrogen-filled glovebox, using an Agilent B2902A parameter analyser. Saturation regime hole mobility $\left(\mu_{\mathrm{sat}}\right)$ values were calculated using the standard gradual channel approximation transistor model:

$\mu_{\text {sat }}=\frac{L}{W C_{\text {ins }}}\left[\frac{\partial^{2} I_{D(s a t)}}{\partial V_{G}^{2}}\right]$

where $\mathrm{C}_{\mathrm{ins}}$ is the geometric capacitance of the gate dielectric, $\mathrm{L}$ is the channel length, and $\mathrm{W}$ is the channel width.

Photovoltaic Cell Fabrication and Characterization: Normal structure organic solar cells were fabricated using PEDOT:PSS and CuSCN as the HTLs. Specifically, as-received aqueous dispersion of PEDOT:PSS (CLEVIOS PH 1000, Heraeus) was spin-cast on ITO-coated glass at $7000 \mathrm{rpm}$ and annealed at $140{ }^{\circ} \mathrm{C}$ for 20 minutes as a reference $\mathrm{HTL}$ film. $\mathrm{NH}_{3}(\mathrm{aq})$-processed CuSCN HTLs were spin-cast at $2000 \mathrm{rpm}$ from $15 \mathrm{mg} \mathrm{ml}^{-1}$ solutions and annealed at $100{ }^{\circ} \mathrm{C}$ in ambient air. Optimized DES-processed CuSCN layers were spin-cast at $3500 \mathrm{rpm}$ from $25 \mathrm{mg}$ $\mathrm{ml}^{-1}$ solutions and annealed at $100{ }^{\circ} \mathrm{C}$ in an $\mathrm{N}_{2}$ atmosphere. For the inverted structure solar cells, zinc acetate $(99.99 \%$, Sigma-Aldrich) was dissolved at $110 \mathrm{mg} / \mathrm{ml}$ in 2-methoxyetahanol (anhydrous, 99.8\%, Sigma-Aldrich) containing 3\% ethanolamine (99.5\%, Sigma-Aldrich), and was subsequently spin-cast on ITO-coated glass at $4000 \mathrm{rpm}$ and then annealed at $150{ }^{\circ} \mathrm{C}$ for 20 minutes in air. Next, the BHJ active layer composed of a 1.5:1 weight ratio blend of PTB7Th (Ossila) and $\mathrm{PC}_{70} \mathrm{BM}$ (Solenne BV), and 3\% of the 1,8-diiodooctane (DIO) additive, was spin-cast at $1750 \mathrm{rpm}$ from a $20 \mathrm{mg} \mathrm{ml}^{-1}$ chlorobenzene solution. A methanol rinse was performed at $4000 \mathrm{rpm}$ immediately after deposition of the active layer. The active layer was dried by placing the samples under a high vacuum $\left(10^{-7} \mathrm{mbar}\right)$ overnight inside the evaporator chamber, after which the cells were completed by the thermal evaporation of a $10 \mathrm{~nm}$-thick layer of bathocuproine (BCP) followed by a $70 \mathrm{~nm}$-thick layer of $\mathrm{Al}$ electrode for the normal structure solar cells, and a 10 nm-thick layer of molybdenum trioxide $\left(\mathrm{MoO}_{3}, 99.97 \%\right.$, Sigma- 
Aldrich) followed by a $70 \mathrm{~nm}$-thick layer of silver electrode for the inverted structure solar cells, through shadow masks. The J-V characteristics of the cells were measured in an inert atmosphere using a Keithley 2400 source-meter. The AM1.5 illumination was provided by a Sciencetech Inc. Solar Simulator SF300-A, with an active area of $5 \mathrm{~mm}^{2}$ defined by a metal stencil mask.

The organometal halide perovskite solar cells were fabricated on ITO-coated glass substrates using CuSCN and PEDOT:PSS as the HTLs. CuSCN was processed from a $\mathrm{NH}_{3}(\mathrm{aq})$ solution $\left(15 \mathrm{mg} \mathrm{ml}^{-1}\right)$ via spin-casting at $3500 \mathrm{rpm}$ and annealed at $150{ }^{\circ} \mathrm{C}$ in ambient air. In contrast to the CuSCN deposition process outlined for the OPV cell fabrication, a higher spin speed was required due to the smaller area of substrates used in perovskite cell fabrication, while a higher annealing temperature was utilized to ensure that the aqueous solvent was evaporated entirely from the CuSCN layer. PEDOT:PSS was spin-cast at $3500 \mathrm{rpm}$ for 45 seconds, and annealed at $150{ }^{\circ} \mathrm{C}$ for 10 minutes. Prior to HTL deposition, the substrates were treated by oxygen plasma for 8 minutes. The precursor solution of organometal halide perovskite was prepared by co-dissolving 1.25 $\mathrm{M}$ lead iodide $\left(\mathrm{PbI}_{2}, 99.5 \%\right.$, Sigma Aldrich) and methylammonium iodide (MAI, Dyesol) in a mixed solvent of gamma-butyrolactone and dimethyl sulfoxide (Sigma Aldrich, 7:3 by volume). The solution was stirred for 2 hours and filtered before use. The precursor solution was first first spun at $500 \mathrm{rpm}$ for $5 \mathrm{~s}$, and then at $2000 \mathrm{rpm}$ for $20 \mathrm{~s} .50 \mathrm{ml}$ of toluene was instantly dripped onto the film at the end of the second stage of spin-casting and followed by a final spin at $4000 \mathrm{rpm}$ for $20 \mathrm{~s}$. The as-deposited semitransparent films were then transferred onto a hotplate and annealed at $100{ }^{\circ} \mathrm{C}$ for 10 minutes. Electron transport layers (ETLs) composed of the phenyl-C 61 -butyricacid methylester $\left(\mathrm{PC}_{60} \mathrm{BM}\right.$, Ossila, UK) were deposited onto the perovskite layer via spin-casting from a chlorobenzene solution $\left(18 \mathrm{mg} \mathrm{ml}^{-1}\right)$ at $1300 \mathrm{rpm}$ for $60 \mathrm{~s}$. Finally, the devices were completed by thermally evaporating a $0.7 \mathrm{~nm}$-thick layer of lithium fluoride (LiF) and $100 \mathrm{~nm}$ of silver (Ag) onto $\mathrm{PC}_{60} \mathrm{BM}$ under high vacuum. With the exception of $\mathrm{CuSCN}$, all other solution 
processing steps were performed inside a nitrogen-filled glovebox. J-V characteristics were recorded with a Keithley 2400 source-meter. The cells were illuminated by an AM1.5 xenon lamp solar simulator (Oriel Instruments). The intensity was adjusted to 1 sun by changing the working current, which was monitored using a calibrated Si reference photodiode. All devices were stored in dark prior to characterization and were measured in a nitrogen-filled chamber.

\section{Supporting Information}

Supporting Information is available from the Wiley Online Library or from the authors.

\section{Acknowledgements}

N.W. Y-H.L, H.F., and T.D.A. are grateful to the to the European Research Council (ERC) AMPRO grant number 280221, and the Engineering and Physical Sciences Research Council (EPSRC) grant number EP/L504786/1, for financial support. D.J.P. acknowledges support from the Royal Society (UF100105) and (UF150693). D.J.P. and A.R. acknowledge support from the EPSRC (EP/M013839/1 and EP/M028291/1). M.A.M. and T.D. are grateful for support through the EPSRC Centre for Doctoral Training in Plastic Electronics EP/L016702/1 and the Stephen and Anna Hui Scholarship (Imperial College London). 


\section{References}

[1] J. E. Jaffe, T. C. Kaspar, T. C. Droubay, T. Varga, M. E. Bowden, G. J. Exarhos, J. Phys. Chem. C 2010, 114, 9111.

[2] P. Pattanasattayavong, N. Yaacobi-Gross, K. Zhao, G. O. N. Ndjawa, J. Li, F. Yan, B. C. O'Regan, A. Amassian, T. D. Anthopoulos, Adv. Mater. 2013, 25, 1504.

[3] P. Pattanasattayavong, A. D. Mottram, F. Yan, T. D. Anthopoulos, Adv. Funct. Mater. 2015, 25, 6802 .

[4] L. Petti, P. Pattanasattayavong, Y. Lin, N. Münzenrieder, G. Cantarella, N. Yaacobi-, F. Yan, G. Tröster, T. D. Anthopoulos, Appl. Phys. Lett. 2017, 110, 113504.

[5] N. Wijeyasinghe, T. D. Anthopoulos, Semicond. Sci. Technol. 2015, 30, 104002.

[6] P. Pattanasattayavong, G. O. N. Ndjawa, K. Zhao, K. W. Chou, N. Yaacobi-Gross, B. C. O’Regan, A. Amassian, T. D. Anthopoulos, Chem. Commun. 2013, 49, 4154.

[7] N. Yaacobi-Gross, N. D. Treat, P. Pattanasattayavong, H. Faber, A. K. Perumal, N. Stingelin, D. D. C. Bradley, P. N. Stavrinou, M. Heeney, T. D. Anthopoulos, Adv. Energy Mater. 2015, 5, 1401529.

[8] N. D. Treat, N. Yaacobi-Gross, H. Faber, A. K. Perumal, D. D. C. Bradley, N. Stingelin, T. D. Anthopoulos, Appl. Phys. Lett. 2015, 107, 013301.

[9] P. Qin, S. Tanaka, S. Ito, N. Tetreault, K. Manabe, H. Nishino, M. K. Nazeeruddin, M. Grätzel, Nat. Commun. 2014, 5, 3834.

[10] K. Zhao, R. Munir, B. Yan, Y. Yang, T. Kim, A. Amassian, J. Mater. Chem. A 2015, 3, 20554.

[11] S. Ye, W. Sun, Y. Li, W. Yan, H. Peng, Z. Bian, Z. Liu, C. Huang, Nano Lett. 2015, 15,3723 .

[12] A. Perumal, H. Faber, N. Yaacobi-Gross, P. Pattanasattayavong, C. Burgess, S. Jha, M. a McLachlan, P. N. Stavrinou, T. D. Anthopoulos, D. D. C. Bradley, Adv. Mater. 2015, $27,93$.

[13] L.-J. Xu, J.-Y. Wang, X.-F. Zhu, X.-C. Zeng, Z.-N. Chen, Adv. Funct. Mater. 2015, 25, 3033.

[14] X. Zhang, S. Yoshioka, N. Loew, M. Ihara, In ECS Transactions 64; 2014; Vol. 64, pp. $1-13$.

[15] S. Yoshioka, T. Mishima, M. Ihara, In ECS Transactions 50; 2013; Vol. 50, pp. 33-44.

[16] S. Ito, S. Tanaka, H. Vahlman, H. Nishino, K. Manabe, P. Lund, ChemPhysChem 2014, 15, 1194. 
[17] E. Bacaksiz, S. Aksu, G. Çankaya, S. Yılmaz, İ. Polat, T. Küçükömeroğlu, A. Varilci, Thin Solid Films 2011, 519, 3679.

[18] S. M. Hatch, J. Briscoe, S. Dunn, Thin Solid Films 2013, 531, 404.

[19] Y. Selk, T. Yoshida, T. Oekermann, Thin Solid Films 2008, 516, 7120.

[20] W. Wu, Z. Jin, Z. Hua, Y. Fu, J. Qiu, Electrochim. Acta 2005, 50, 2343.

[21] B. O’Regan, D. T. Schwartz, S. M. Zakeeruddin, M. Grätzel, Adv. Mater. 2000, 12, 1263.

[22] C. Chappaz-Gillot, R. Salazar, S. Berson, V. Ivanova, Electrochim. Acta 2013, 110, 375 .

[23] E. Fortunato, V. Figueiredo, P. Barquinha, E. Elamurugu, R. Barros, G. Gonçalves, S.H. K. Park, C.-S. Hwang, R. Martins, Appl. Phys. Lett. 2010, 96, 192102.

[24] J. Caraveo-Frescas, P. Nayak, H. Al-Jawhari, D. Granato, U. Schwingenschloegl, H. Alshareef, ACS Nano 2013, 7, 5160.

[25] M. D. Irwin, D. B. Buchholz, A. W. Hains, R. P. H. Chang, T. J. Marks, PNAS 2008, 105, 2783.

[26] D. Muñoz-Rojas, M. Jordan, C. Yeoh, A. T. Marin, A. Kursumovic, L. A. Dunlop, D.

C. Iza, A. Chen, H. Wang, J. L. MacManus Driscoll, AIP Adv. 2012, 2, 042179.

[27] S.-Y. Sung, S.-Y. Kim, K.-M. Jo, J.-H. Lee, J.-J. Kim, S.-G. Kim, K.-H. Chai, S. J. Pearton, D. P. Norton, Y.-W. Heo, Appl. Phys. Lett. 2010, 97, 222109.

[28] Y. Ogo, H. Hiramatsu, K. Nomura, H. Yanagi, T. Kamiya, M. Hirano, H. Hosono, Appl. Phys. Lett. 2008, 93, 032113.

[29] P. Pattanasattayavong, S. Thomas, G. Adamopoulos, M. A. McLachlan, T. D. Anthopoulos, Appl. Phys. Lett. 2013, 102, 163505.

[30] S. R. Thomas, P. Pattanasattayavong, T. D. Anthopoulos, Chem. Soc. Rev. 2013, 42, 6910.

[31] K. Sun, S. Zhang, P. Li, Y. Xia, X. Zhang, D. Du, F. H. Isikgor, J. Ouyang, J. Mater. Sci. Mater. Electron. 2015, 26, 4438.

[32] A. Garcia, G. C. Welch, E. L. Ratcliff, D. S. Ginley, G. C. Bazan, D. C. Olson, $A d v$. Mater. 2012, 24, 5368.

[33] M. P. de Jong, L. J. van IJzendoorn, M. J. A. de Voigt, Appl. Phys. Lett. 2000, 77, 2255.

[34] G. R. R. A. Kumara, A. Konno, G. K. R. Senadeera, P. V. V Jayaweera, D. B. R. A. De Silva, K. Tennakone, Sol. Energy Mater. Sol. Cells 2001, 69, 195. 
[35] CLH Report. Proposal for harmonised classification and labelling. Substance name: copper thiocyanate or copper (I) thiocyanate or cuprous thiocyanate; 2013; Vol. 2008, pp. 1-191.

[36] N. Chaudhary, R. Chaudhary, J. P. Kesari, A. Patra, Opt. Mater 2017, 69, 367.

[37] K. M. Miller, S. M. McCullough, E. A. Lepekhina, I. J. Thibau, R. D. Pike, X. Li, J. P. Killarney, H. H. Patterson, Inorg. Chem. 2011, 50, 7239.

[38] A. Blake, N. Champness, M. Crew, L. Hanton, S. Parsons, M. Schroeder, J. Chem. Soc. Dalt. Trans. 1998, 1533.

[39] A. Blake, N. Brooks, N. Champness, C. Marcello, L. Hanton, P. Hubberstey, S. Parsons, M. Schröder, J. Chem. Soc. Dalt. Trans. 1999, 2813.

[40] G. Ayala, T. A. Tronic, R. D. Pike, Polyhedron 2016, 115, 257.

[41] D. Tudela, J. Chem. Educ. 1993, 70, 174.

[42] J. Hunter, W. Massie, J. Meiklejohn, J. Reid, Inorg. Nucl. Chem. Lett. 1969, 5, 1.

[43] K. Tennakone, A. H. Jayatissa, C. A. N. Fernando, S. Wickramanayake, S. Punchihewa, L. K. Weerasena, W. D. R. Premasiri, Phys. Status Solidi A 1987, 103, 491.

[44] Y. Ni, Z. Jin, Y. Fu, J. Am. Ceram. Soc. 2007, 90, 2966.

[45] X.-D. Gao, X.-M. Li, W.-D. Yu, J.-J. Qiu, X.-Y. Gan, Thin Solid Films 2008, 517, 554.

[46] B. J. Hathaway, A. A. G. Tomlinson, Coord. Chem. Rev. 1970, 5, 1.

[47] K. Koyama, M. Tanaka, J. Lee, Mater. Trans. 2006, 47, 1788.

[48] X. Jiang, Y. Xie, J. Lu, W. He, L. Zhu, Y. Qian, J. Mater. Chem. 2000, 10, 2193.

[49] L. Tsetseris, J. Phys. Condens. Matter 2016, 28, 295801.

[50] P. Peumans, S. R. Forrest, Appl. Phys. Lett. 2001, 79, 126.

[51] D. C. Oertel, M. G. Bawendi, A. C. Arango, V. Bulović, Appl. Phys. Lett. 2005, 87, 213505.

[52] K. Khojier, H. Savaloni, Z. Sadeghi, J. Theor. Appl. Phys. 2014, 8, 116.

[53] R. X. Wang, C. D. Beling, S. Fung, a. B. Djurišić, C. C. Ling, S. Li, J. Appl. Phys. 2005, 97, 033504.

[54] P. Giannozzi, S. Baroni, N. Bonini, M. Calandra, R. Car, C. Cavazzoni, D. Ceresoli, G. L. Chiarotti, M. Cococcioni, I. Dabo, A. Dal Corso, S. de Gironcoli, S. Fabris, G. Fratesi, R. Gebauer, U. Gerstmann, C. Gougoussis, A. Kokalj, M. Lazzeri, L. MartinSamos, N. Marzari, F. Mauri, R. Mazzarello, S. Paolini, A. Pasquarello, L. Paulatto, C. 
Sbraccia, S. Scandolo, G. Sclauzero, A. P. Seitsonen, A. Smogunov, P. Umari, R. M. Wentzcovitch, J. Phys. Condens. Matter 2009, 21, 395502.

[55] L. Tsetseris, Phys. Chem. Chem. Phys. 2016, 18, 7837.

[56] L. Tsetseris, Phys. Chem. Chem. Phys. 2016, 18, 14662.

[57] D. Aldakov, C. Chappaz-Gillot, R. Salazar, V. Delaye, K. Welsby, V. Ivanova, P. Dunstan, J. Phys. Chem. C 2014, 118, 16095.

[58] N. McIntyre, M. Cook, Anal. Chem. 1975, 47, 2208.

[59] J. Klein, A. Proctor, D. Hercules, J. Black, Anal. Chem. 1983, 55, 2055.

[60] C. D. Wagner, J. A. Taylor, J. Electron Spectros. Relat. Phenomena 1980, $20,83$.

[61] D. Perry, J. Taylor, J. Mater. Sci. Lett. 1986, 5, 384.

[62] J. Yeh, I. Lindau, At. Data Nucl. Data Tables 1985, 32, 1.

[63] W. L. Kalb, B. Batlogg, Phys. Rev. B 2010, 81, 035327.

[64] J. Jeong, J. Seo, S. Nam, H. Han, H. Kim, T. D. Anthopoulos, D. D. C. Bradley, Y. Kim, Adv. Sci. 2016, 3, 1500269.

[65] B. J. Tremolet de Villers, K. a. O’Hara, D. P. Ostrowski, P. H. Biddle, S. E. Shaheen, M. L. Chabinyc, D. C. Olson, N. Kopidakis, Chem. Mater. 2016, 28, 876.

[66] S. Chavhan, O. Miguel, H.-J. Grande, V. Gonzalez-Pedro, R. S. Sánchez, E. M. Barea, I. Mora-Seró, R. Tena-Zaera, J. Mater. Chem. A 2014, 2, 12754.

[67] J. W. Jung, C. Chueh, A. K. Jen, Adv. Energy Mater. 2015, 5, 1500486.

[68] A. Kojima, K. Teshima, Y. Shirai, T. Miyasaka, J. Am. Chem. Soc. 2009, 131, 6050.

[69] H.-S. Kim, C.-R. Lee, J.-H. Im, K.-B. Lee, T. Moehl, A. Marchioro, S.-J. Moon, R. Humphry-Baker, J.-H. Yum, J. E. Moser, M. Grätzel, N.-G. Park, Sci. Rep. 2012, 2 , 591.

[70] M. M. Lee, J. Teuscher, T. Miyasaka, T. N. Murakami, Snaith Henry J, Science 2012, $338,643$.

[71] S. D. Stranks, H. J. Snaith, Nat. Nanotechnol. 2015, 10, 391.

[72] S. Ye, H. Rao, W. Yan, Y. Li, W. Sun, H. Peng, Z. Liu, Z. Bian, Y. Li, C. Huang, Adv. Mater. 2016, 28, 9648.

[73] J. Seo, S. Park, Y. C. Kim, N. J. Jeon, J. H. Noh, S. C. Yoon, S. Il Seok, Energy Environ. Sci. 2014, 7, 2642. 
[74] J. H. Park, J. Seo, S. Park, S. S. Shin, Y. C. Kim, N. J. Jeon, H.-W. Shin, T. K. Ahn, J. H. Noh, S. C. Yoon, C. S. Hwang, S. Il Seok, Adv. Mater. 2015, 27, 4013.

[75] C. Bi, Q. Wang, Y. Shao, Y. Yuan, Z. Xiao, J. Huang, Nat. Commun. 2015, 6, 7747.

[76] J. Vicente, M. Díaz, Environ. Sci. Technol. 2003, 37, 1452. 


\section{Figures}
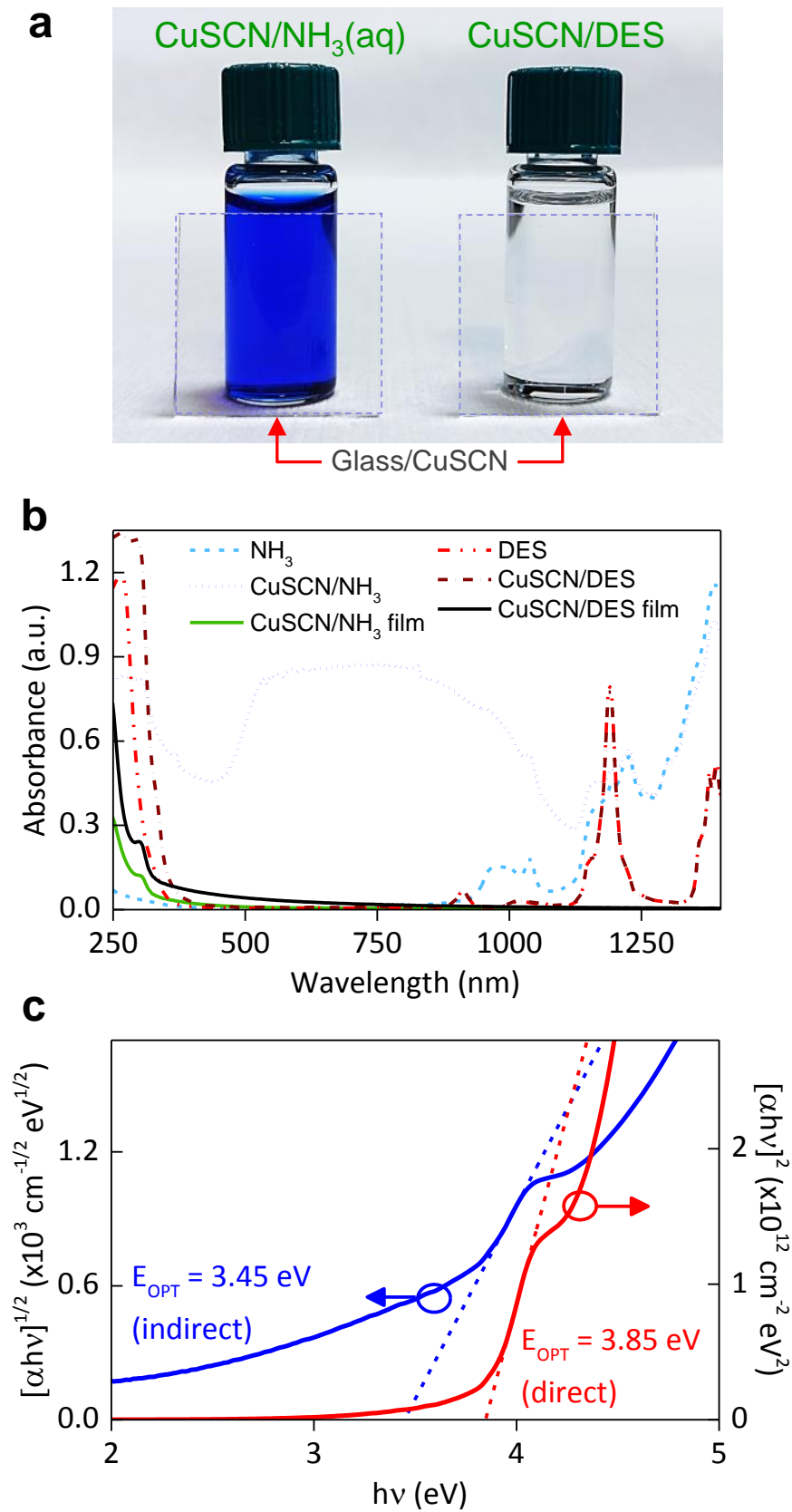

Figure 1. a) Photographs of the vials containing the $\mathrm{CuSCN} / \mathrm{NH}_{3}(\mathrm{aq})$ and $\mathrm{CuSCN} / \mathrm{DES}$ solutions placed behind $2 \times 2 \mathrm{~cm}^{2}$ glass substrates coated with thin layers of CuSCN. (b) UVVis-NIR absorbance spectra of CuSCN solutions, relevant solvents, and thin-films of CuSCN spin-cast on quartz substrates and thermally annealed at $100{ }^{\circ} \mathrm{C}$, for comparison. (c) Tauc plots of $(\alpha h v)^{2}$ and $(\alpha h v)^{1 / 2}$ calculated from absorbance spectra of the $\mathrm{NH}_{3}(\mathrm{aq})$-processed CuSCN layers on quartz. From the linear regions an indirect bandgap of $3.45( \pm 0.05) \mathrm{eV}$ and a direct bandgap of $3.85( \pm 0.05) \mathrm{eV}$, were extracted. 

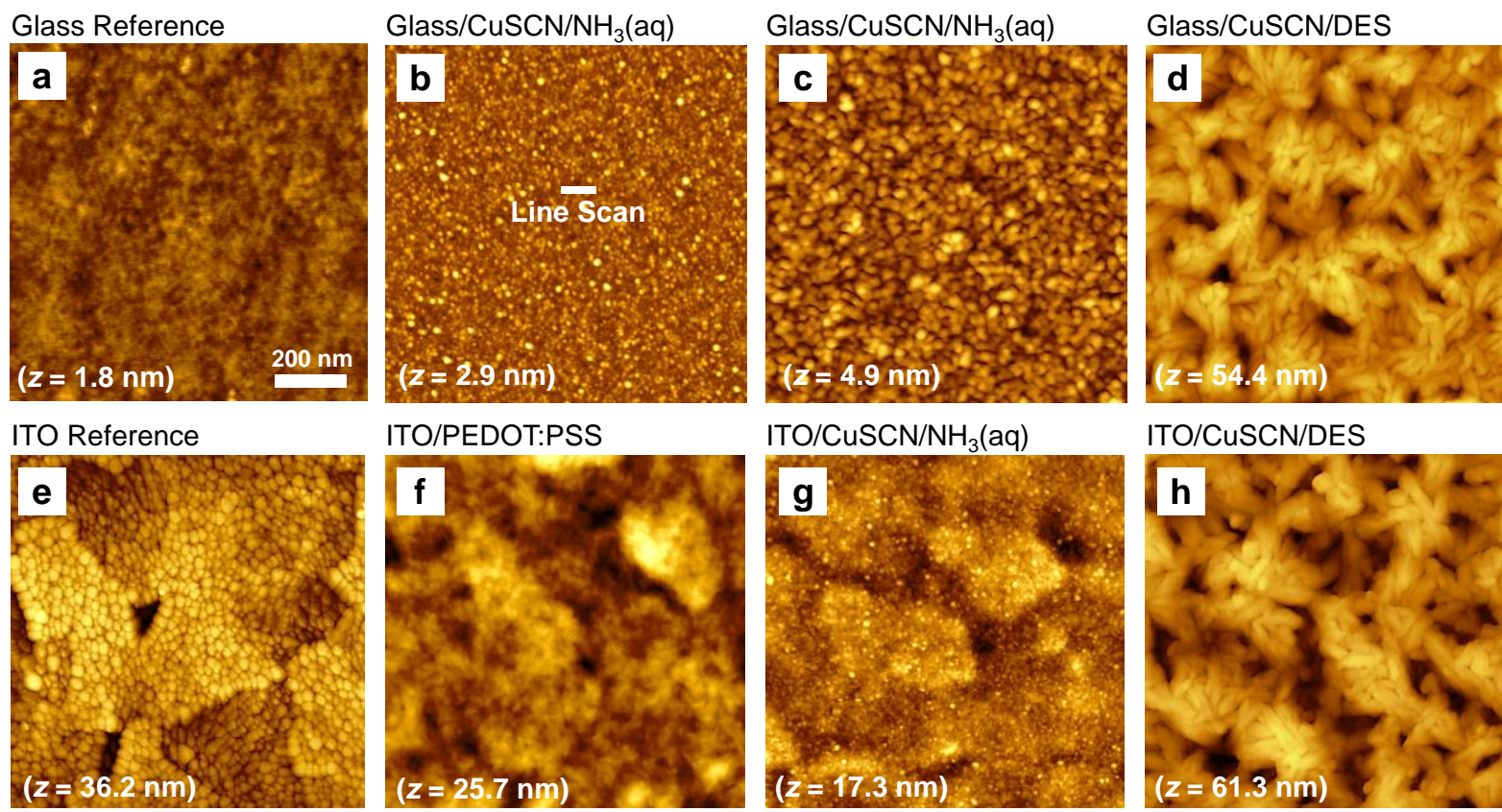

ITO/PEDOT:PSS

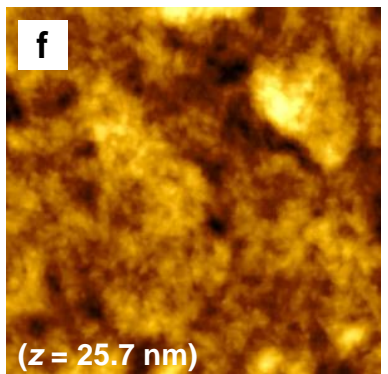

ITO/CuSCN/NH$/(a q)$

ITO/CUSCN/DES
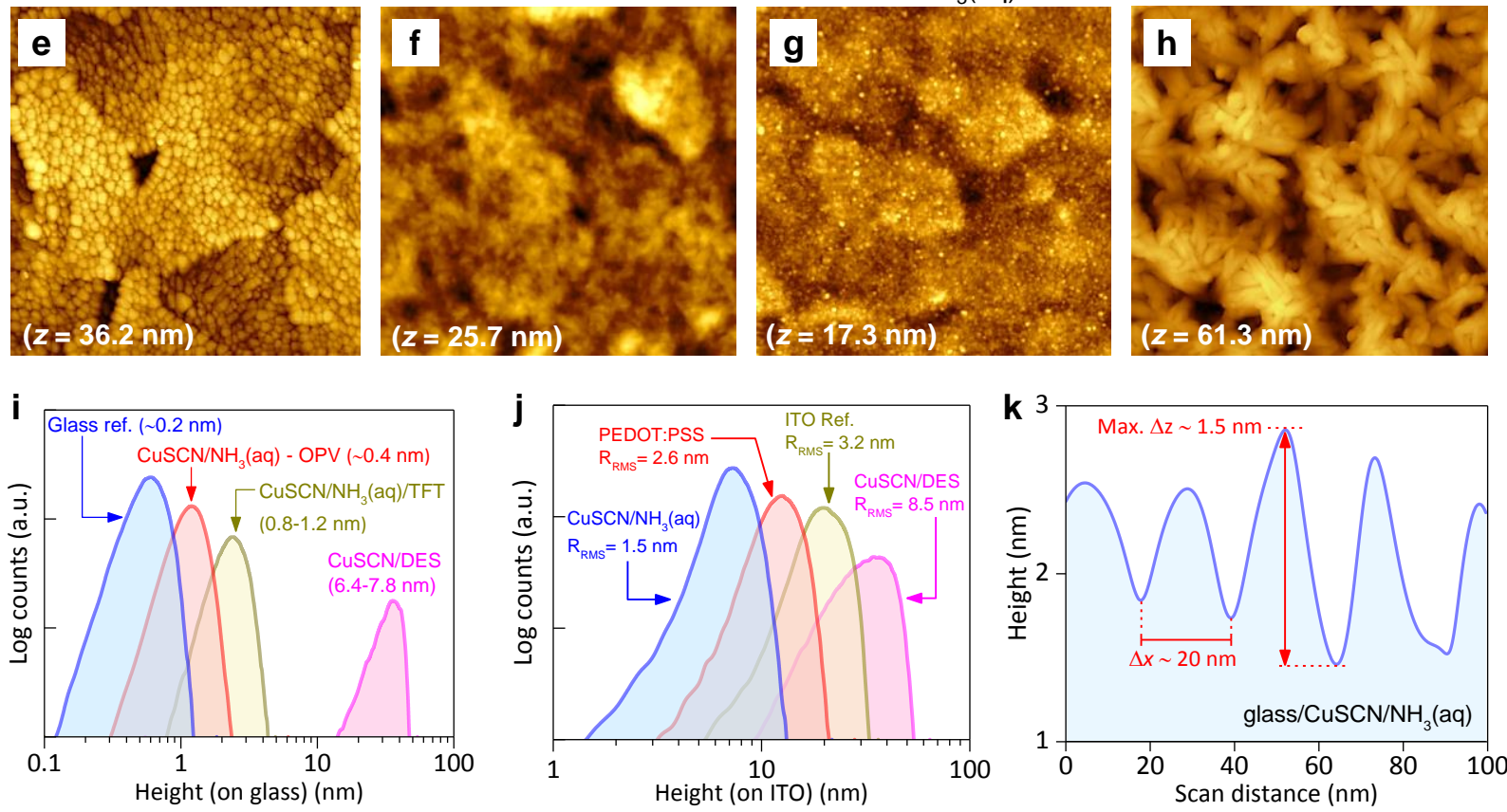

Figure 2. (a-h) AFM surface topography images of various samples, namely; (a) glass substrate, (b) $\mathrm{CuSCN} / \mathrm{NH}_{3}$ (aq) spin-cast on glass at $2000 \mathrm{rpm}$ from a $15 \mathrm{mg} \mathrm{ml}^{-1}$ solution. (c) $\mathrm{CuSCN} / \mathrm{NH}_{3}$ (aq) spin-cast on glass at $800 \mathrm{rpm}$ from a $10 \mathrm{mg} \mathrm{ml}^{-1}$ solution. (d) CuSCN/DES spin-cast on glass at $800 \mathrm{rpm}$ from a $10 \mathrm{mg} \mathrm{ml}^{-1}$ solution. (e) Glass/ITO surface. (f) PEDOT:PSS spin-cast on glass/ITO at $7000 \mathrm{rpm}$ and annealed at $140{ }^{\circ} \mathrm{C}$. This layer was optimized for HTL applications. (g) CuSCN/NH 3 spin-cast on glass/ITO at $2000 \mathrm{rpm}$ from a $15 \mathrm{mg} \mathrm{ml}^{-1}$ solution. (h) CuSCN/DES spin-cast on glass/ITO at $2000 \mathrm{rpm}$ from a $15 \mathrm{mg} \mathrm{ml}^{-1}$ solution. (i-j) Height histograms extracted from the AFM data shown in (a-h). The 'OPV' and 'TFT' labels indicate layers spin-cast at $2000 \mathrm{rpm}$ from a $15 \mathrm{mg} \mathrm{ml}^{-1}$ solution and at $800 \mathrm{rpm}$ from a $10 \mathrm{mg} \mathrm{ml}^{-1}$ solution, respectively. (k) Line scan obtained from the highlighted region in (b). In all topography images, lighter colours correspond to higher regions of the surface where the specified $\mathrm{z}$-values denote the maximum height relative to the minimum at $\mathrm{z}=0$. 


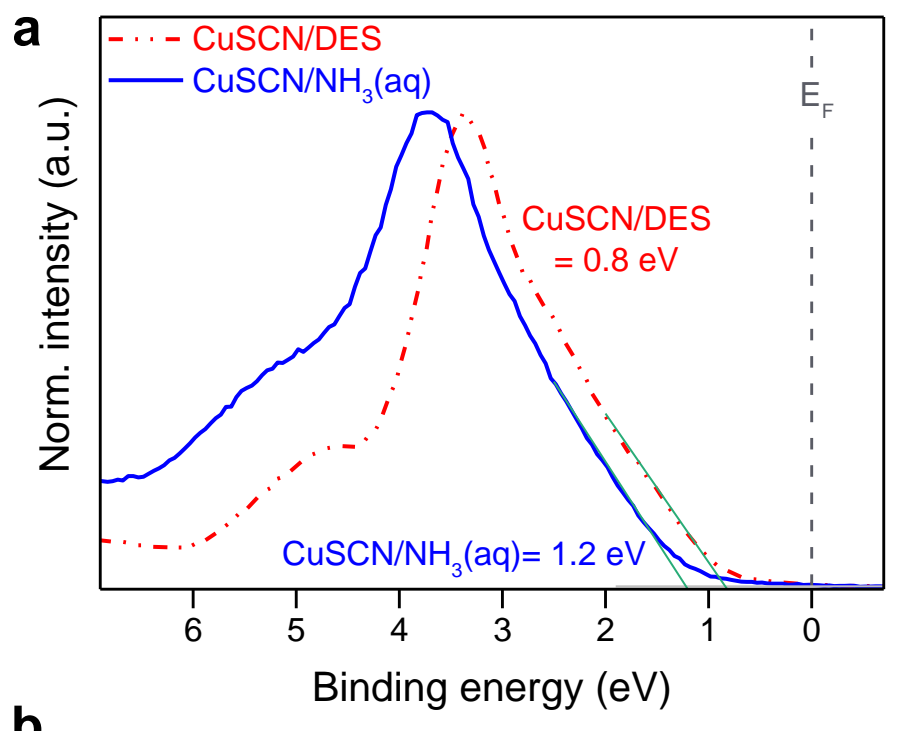

b

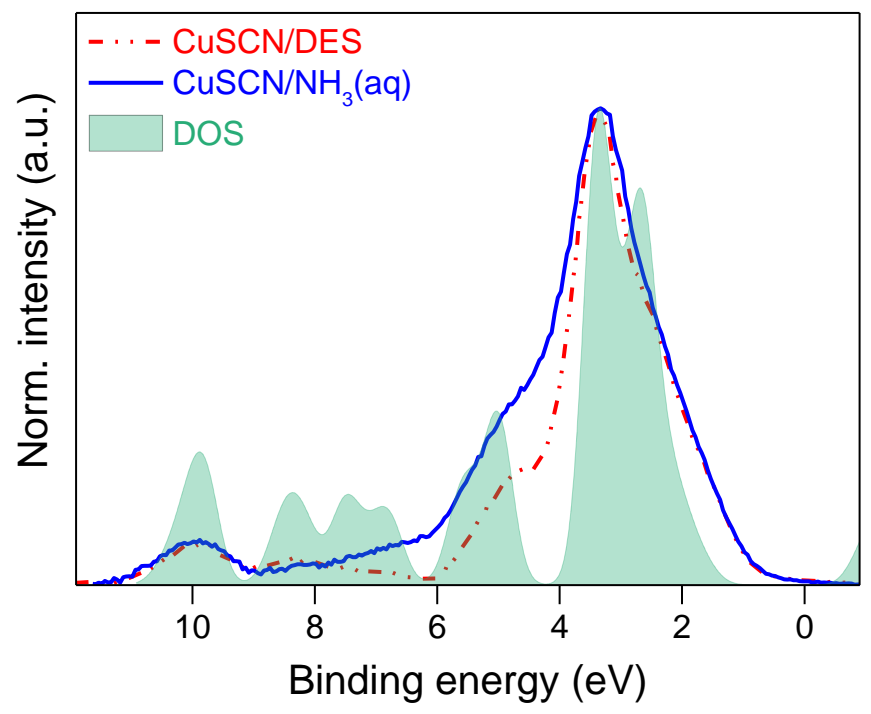

Figure 3. (a) Valence band spectra of CuSCN/DES and CuSCN/NH 3 (aq) layers where the position of the $\mathrm{VB}_{\max }$ with respect to $\mathrm{E}_{\mathrm{F}}$ is also shown. (b) Experiment and one electron cross section corrected density of states (DOS) for CuSCN/DES and CuSCN/NH $\mathrm{NH}_{3}$ (aq) layers from DFT calculations. In (b) the data sets from (a) are aligned to the position of the $\mathrm{Cu} 3 d$ contribution of CuSCN/DES. 


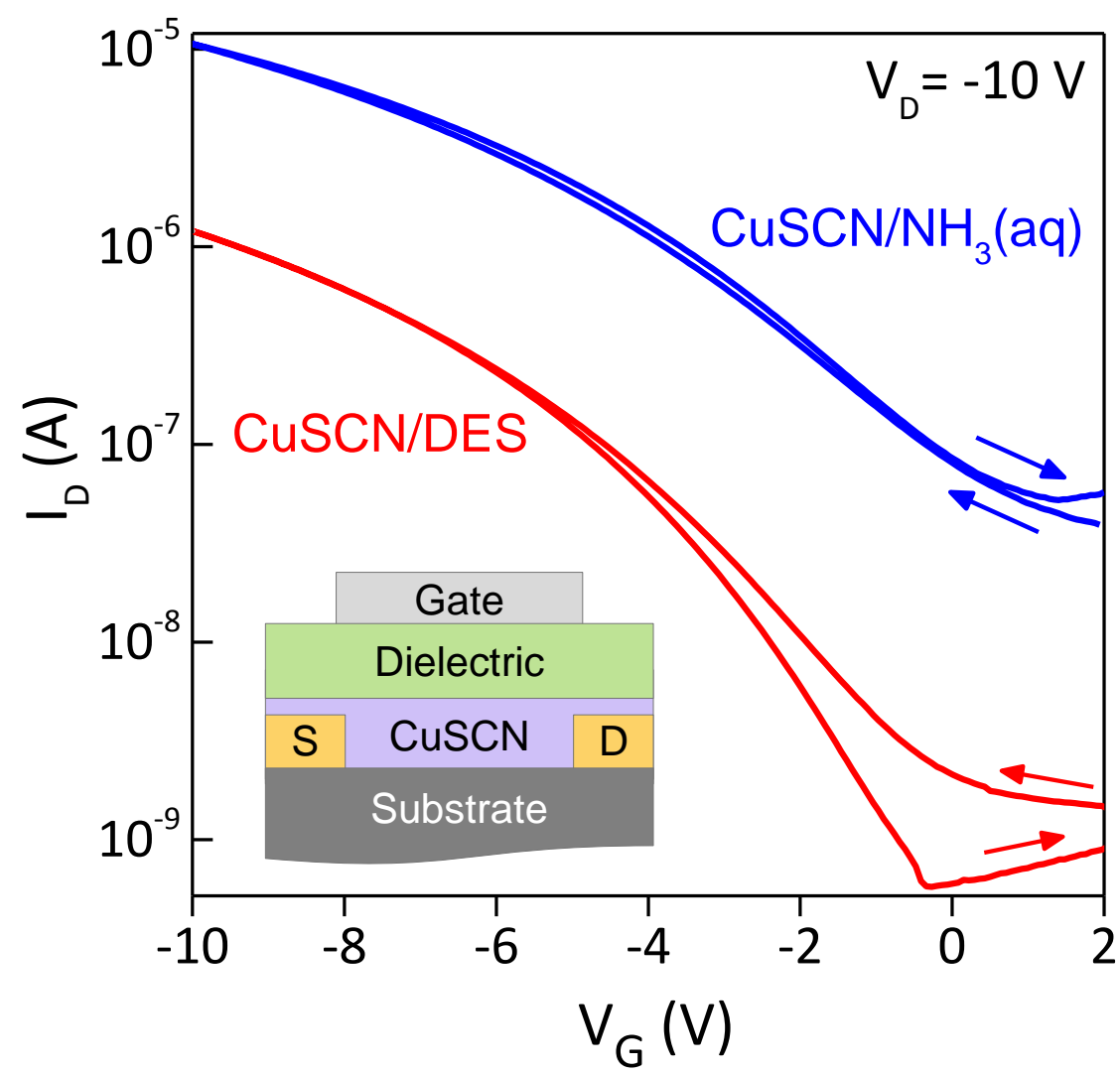

Figure 4. Transfer characteristics of a CuSCN TFT processed via spin-casting from a $\mathrm{CuSCN} / \mathrm{NH}_{3}(\mathrm{aq})$ solution. Inset shows a schematic of the staggered TG-BC transistor architecture employed with Au S-D contacts and Al gate electrode. The channel dimensions of the transistor are $\mathrm{L}=30 \mu \mathrm{m}$ and $\mathrm{W}=1000 \mu \mathrm{m}$. 
a

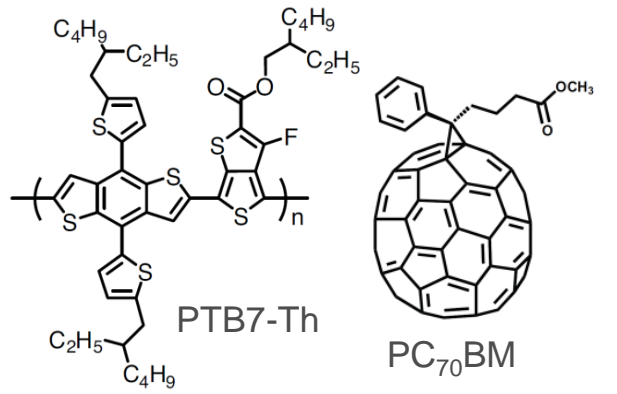

d

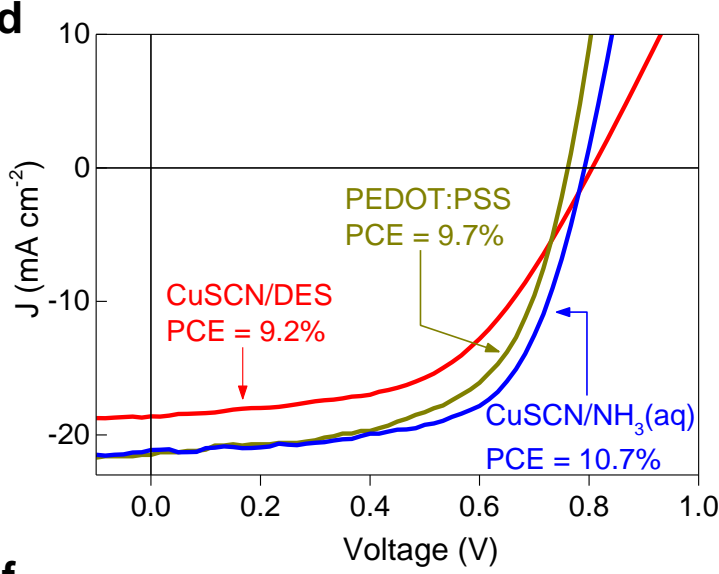

f

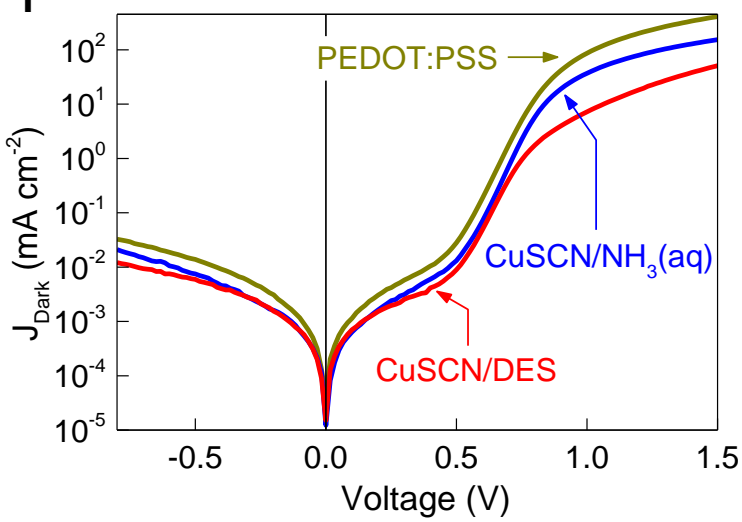

b

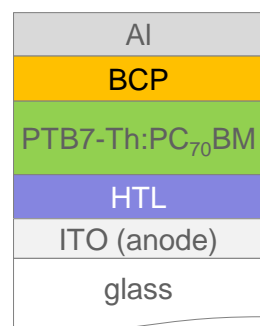

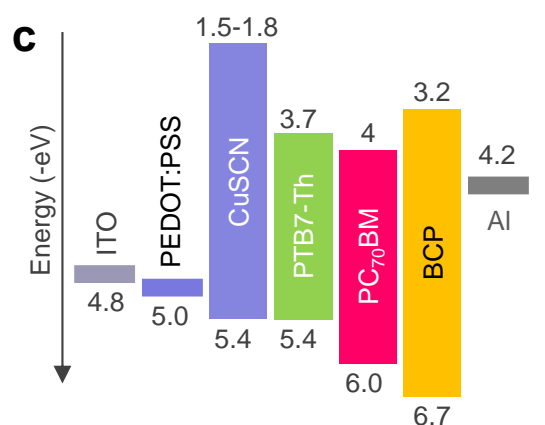

e

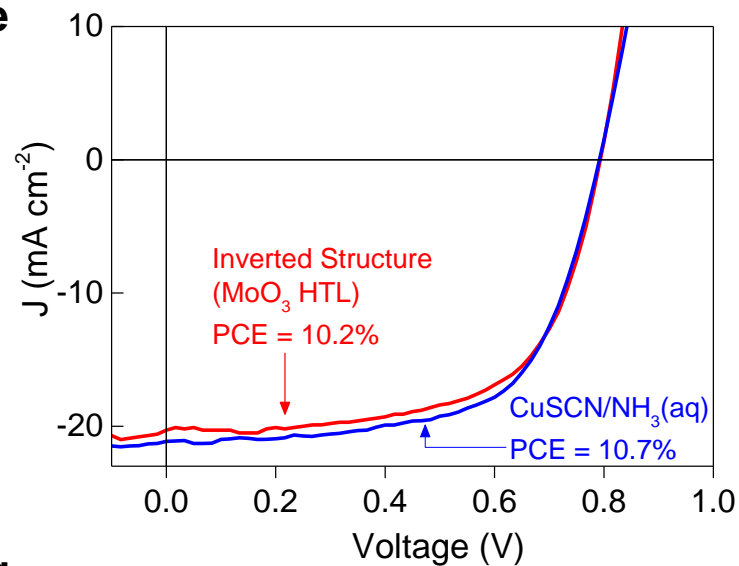

g

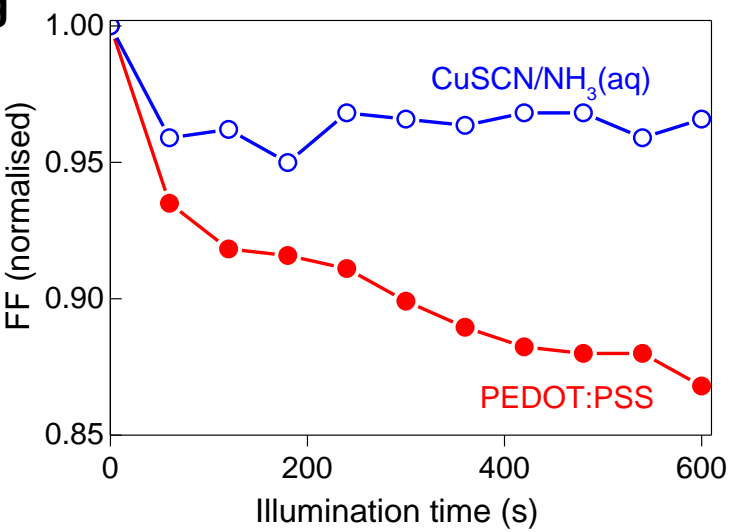

Figure 5. (a) Chemical structures of the active blend components PTB7-Th and PC $70 \mathrm{BM}$. (b) Schematic cross-section of the standard cell architecture employed. (c) Energetics of the various materials employed. (d) $\mathrm{J}-\mathrm{V}$ characteristics measured under simulated solar light illumination for standard PTB7-Th:PC ${ }_{70} \mathrm{BM}$ OPV cells based on three different HTLs, namely; $\mathrm{CuSCN} / \mathrm{DES}, \mathrm{CuSCN} / \mathrm{NH}_{3}$ (aq) and PEDOT:PSS. (e) J-V characteristics of a standard and an inverted PTB7-Th:PC $70 \mathrm{BM}$ cell. In the case of the inverted cell, $\mathrm{MoO}_{3}$ was used as the HTL. (f) Dark J-V characteristics measured for the three OPV cells shown in (d). (g) Normalized stability curves of FF of samples with PEDOT:PSS and CuSCN/NH$H_{3}(\mathrm{aq}) \mathrm{HTLs}$. 
a

\begin{tabular}{|c|}
\hline $\mathrm{Ag}$ \\
\hline $\mathrm{PC}_{60} \mathrm{BM}$ \\
\hline $\mathrm{CH}_{3} \mathrm{NH}_{3} \mathrm{Pbl}_{3}$ \\
\hline $\mathrm{HTL}$ \\
\hline $\mathrm{ITO}$ (anode) \\
\hline glass \\
\hline
\end{tabular}

b

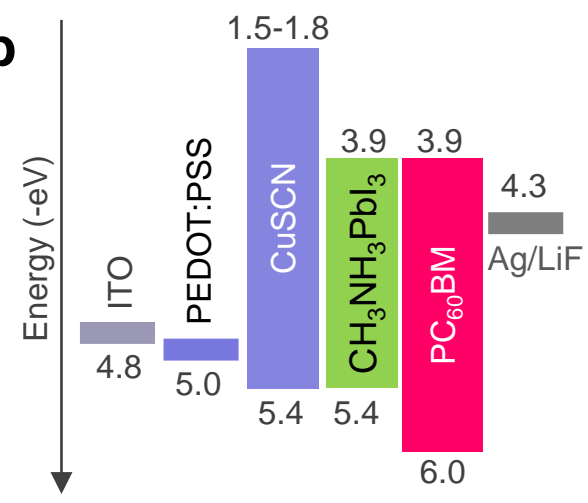

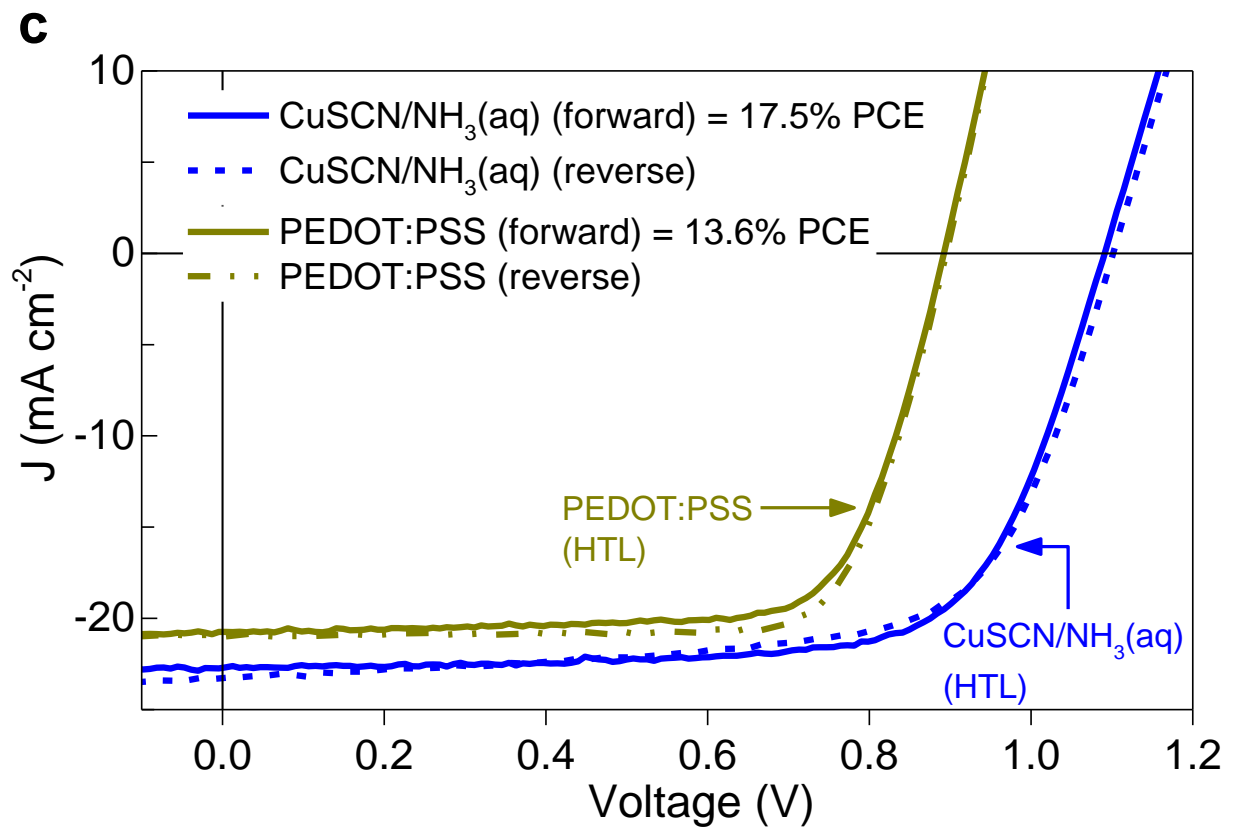

Figure 6. (a) Schematic cross-section of the cell architecture employed, and (b) corresponding material energetics. (c) J-V characteristics measured under simulated solar illumination for two $\mathrm{CH}_{3} \mathrm{NH}_{3} \mathrm{PbI}_{3}$ solar cells based on CuSCN/NH${ }_{3}(\mathrm{aq})$ and PEDOT:PSS HTLs. 
Table 1. Summary of the device parameters of TG-BC CuSCN transistors processed from $\mathrm{NH}_{3}$ (aq) and DES solutions. The channel length and width of all transistors were 30 and 1000 $\mu \mathrm{m}$, respectively.

\begin{tabular}{lllllll}
\hline Solvent & $\begin{array}{l}\mu_{\text {lin }}{ }^{\mathrm{a})} \\
\left(\mathrm{cm}^{2} \mathrm{~V}^{-1} \mathrm{~s}^{-1}\right)\end{array}$ & $\begin{array}{l}\mu_{\mathrm{sat}^{\mathrm{a}}}{ }^{\mathrm{a}} \\
\left(\mathrm{cm}^{2} \mathrm{~V}^{-1} \mathrm{~s}^{-1}\right)\end{array}$ & $\begin{array}{l}\text { On/off } \\
\text { ratio }\end{array}$ & $\begin{array}{l}\mathrm{V}_{\text {on }}{ }^{\mathrm{b})} \\
(\mathrm{V})\end{array}$ & $\begin{array}{l}\mathrm{V}_{\mathrm{th}}^{\mathrm{b})} \\
(\mathrm{V})\end{array}$ & $\begin{array}{l}\mathrm{SS} \\
\left(\mathrm{V} \mathrm{dec}^{-1}\right)\end{array}$ \\
\hline $\mathrm{DES}$ & $0.01(0.01)$ & $0.01(0.02)$ & $2 \times 10^{3}$ & -0.3 & -3.1 & $1-2$ \\
$\mathrm{NH}_{3}(\mathrm{aq})$ & $0.04(0.05)$ & $0.05(0.07)$ & $4 \times 10^{2}$ & 1.0 & -2.1 & $2-3$ \\
\hline
\end{tabular}

a) Mean values obtained from five TFTs; data from the 'champion' device is given in brackets. The standard deviation is $0.01 \mathrm{~cm}^{2} \mathrm{~V}^{-1} \mathrm{~s}^{-1}$.

${ }^{b)}$ Mean values extracted from saturation regime data. The standard deviation is $0.3 \mathrm{~V}$.

Table 2. Summary of operating parameters for PTB7-Th:PC $70 \mathrm{BM}$ OPV cells made with different HTLs.

\begin{tabular}{lclcc}
\hline $\left.\mathrm{HTL}^{\mathrm{a}}\right)$ & $\mathrm{J}_{\mathrm{SC}}\left(\mathrm{mA} \mathrm{cm}^{-2}\right)$ & $\mathrm{V}_{\mathrm{OC}}(\mathrm{V})$ & $\mathrm{FF}$ & $\mathrm{PCE}(\%)$ \\
\hline PEDOT:PSS & $19.2(21.5)$ & $0.76(0.77)$ & $0.60(0.60)$ & $9.10(9.67)$ \\
$1 \times \mathrm{CuSCN} / \mathrm{NH}_{3}(\mathrm{aq})^{\mathrm{b}}$ & $20.1(20.5)$ & $0.78(0.78)$ & $0.62(0.63)$ & $9.30(10.12)$ \\
$2 \times \mathrm{CuSCN} / \mathrm{NH}_{3}(\mathrm{aq})^{\mathrm{b}}$ & $20.0(21.1)$ & $0.79(0.80)$ & $0.63(0.63)$ & $10.01(10.70)$ \\
$3 \times \mathrm{CuSCN} / \mathrm{NH}_{3}(\mathrm{aq})^{\mathrm{b}}$ & $18.0(20.1)$ & $0.78(0.78)$ & $0.59(0.61)$ & $9.25(9.46)$ \\
$\mathrm{CuSCN} / \mathrm{DES}$ & $19.4(20.8)$ & $0.79(0.80)$ & $0.54(0.57)$ & $8.33(9.15)$ \\
$\mathrm{MoO}_{3}$ (Inverted) & $19.0(20.3)$ & $0.79(0.80)$ & $0.64(0.65)$ & $9.68(10.20)$
\end{tabular}

a) Mean values obtained from eight cells; data from the 'champion' cell is given in brackets.

${ }^{b)}$ Data from cells containing single, double and triple-spun $\mathrm{CuSCN} / \mathrm{NH}_{3}(\mathrm{aq})$ layers.

Table 3. Summary of operating parameters for $\mathrm{CH}_{3} \mathrm{NH}_{3} \mathrm{PbI}_{3}$ perovskite solar cells containing $\mathrm{CuSCN} / \mathrm{NH}_{3}(\mathrm{aq})$ and PEDOT:PSS HTLs.

\begin{tabular}{lllll}
\hline $\mathrm{HTL}^{\text {a) }}$ & $\begin{array}{l}\mathrm{J}_{\mathrm{SC}} \\
\left(\mathrm{mA} \mathrm{cm}^{-2}\right)\end{array}$ & $\begin{array}{l}\mathrm{V}_{\mathrm{OC}} \\
(\mathrm{V})\end{array}$ & FF & $\begin{array}{l}\text { PCE } \\
(\%)\end{array}$ \\
\hline PEDOT:PSS & $18.3(20.7)$ & $0.89(0.90)$ & $0.73(0.73)$ & $12.4(13.6)$ \\
CuSCN/NH & & & & \\
& $22.3(22.7)$ & $1.09(1.10)$ & $0.71(0.71)$ & $17.2(17.5)$
\end{tabular}

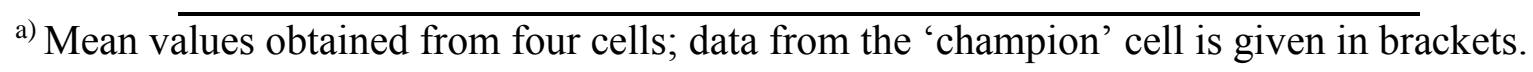


Dissolution of copper thiocyanate $(\mathrm{CuSCN})$ in aqueous ammonia enables processing of superior quality hole transporting layers at low temperature in ambient air. Transistors and solar cells based on these CuSCN layers exhibit mobilities close to $0.1 \mathrm{~cm}^{2} / \mathrm{Vs}$ and power conversion efficiency of $10.7 \%$ and $17 \%$ for organic bulk-heterojunction and organometal halide cells, respectively.

Keywords: Copper(I) thiocyanate; hole transport layers; organic solar cells; perovskite solar cells; transparent semiconductors and transistors

Nilushi Wijeyasinghe, Anna Regoutz, Flurin Eisner, Tian Du, Leonidas Tsetseris, Yen-Hung Lin, Hendrik Faber, Pichaya Pattanasattayavong, Jinhua Li, Feng Yan, Martyn A. McLachlan, David J. Payne, Martin Heeney and Thomas D. Anthopoulos

Copper(I) Thiocyanate (CuSCN) Hole-Transport Layers Processed from Aqueous Precursor Solutions and Their Application in Thin-Film Transistors and Highly Efficient Organic and Organometal Halide Perovskite Solar Cells

\section{ToC Figure}
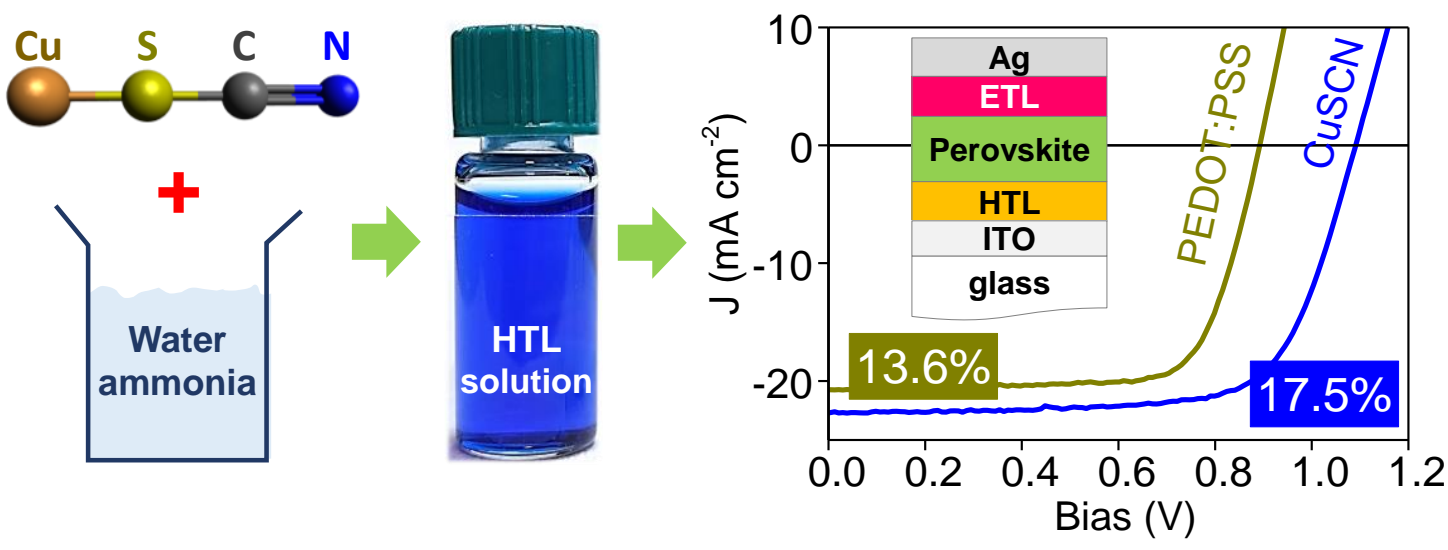


\section{Supporting Information}

\section{Copper(I) Thiocyanate (CuSCN) Hole-Transport Layers Processed from Aqueous Precursor Solutions and Their Application in Thin-Film Transistors and Highly Efficient Organic and Organometal Halide Perovskite Solar Cells}

Nilushi Wijeyasinghe, Anna Regoutz, Flurin Eisner, Tian Du, Leonidas Tsetseris, Yen-Hung Lin, Hendrik Faber, Pichaya Pattanasattayavong, Jinhua Li, Feng Yan, Martyn A. McLachlan, David J. Payne, Martin Heeney and Thomas D. Anthopoulos*

\section{S1. UV-Vis-NIR Spectroscopy}

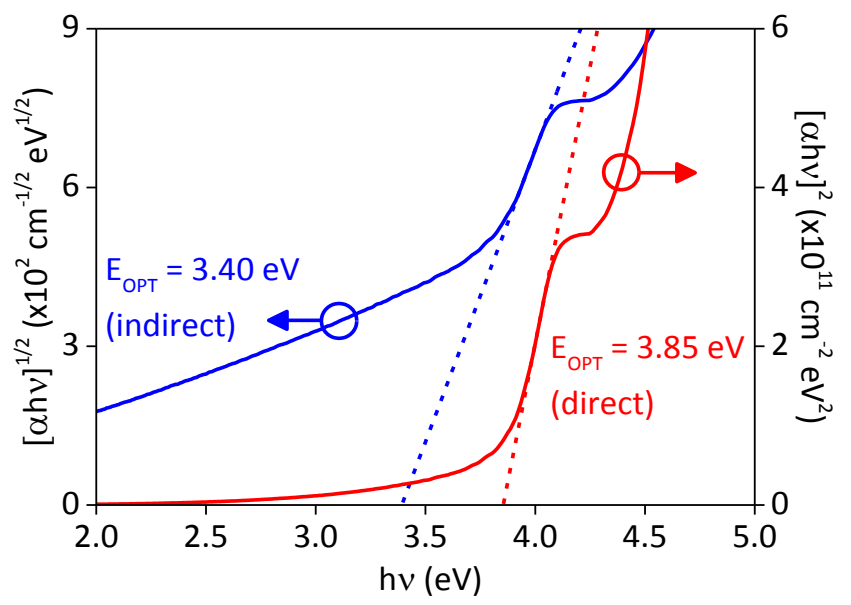

Figure S1. Plots of $(\alpha h v)^{2}$ and $(\alpha h v)^{1 / 2}$ calculated from absorbance measurements of a DESprocessed $\mathrm{CuSCN}$ layer on quartz. The linear regions correspond to an indirect bandgap of 3.40 $( \pm 0.05) \mathrm{eV}$ and a direct bandgap of $3.85( \pm 0.05) \mathrm{eV}$.

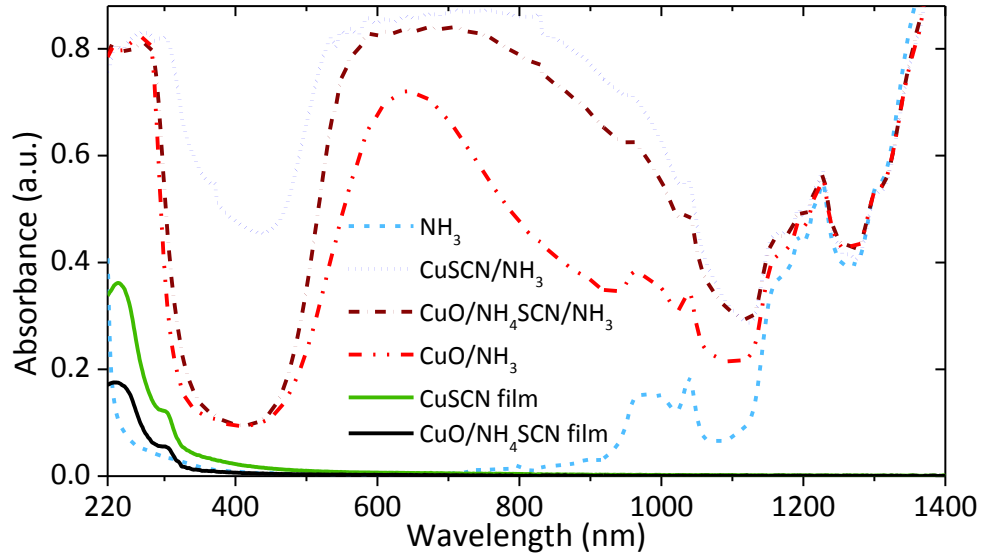

Figure S2. UV-Vis-NIR absorbance spectra of the aqueous ammonia-based solutions containing $\mathrm{CuSCN}$ and $\mathrm{CuO} / \mathrm{NH}_{4} \mathrm{SCN}$ precursors; the spectra of layers spin-cast on quartz and annealed at $100{ }^{\circ} \mathrm{C}$ are shown for comparison. The deep blue colour of $\mathrm{CuSCN} / \mathrm{NH}_{3}$ and $\mathrm{CuO} / \mathrm{NH}_{4} \mathrm{SCN} / \mathrm{NH}_{3}$ solutions correspond to strong absorption in the 550-700 nm spectral region. Notably, the $\mathrm{CuO} / \mathrm{NH}_{4} \mathrm{SCN} / \mathrm{NH}_{3}$ and $\mathrm{CuSCN} / \mathrm{NH}_{3}$ spectra exhibit remarkably similar 
absorption features, but in contrast, $\mathrm{CuO} / \mathrm{NH}_{3}$ exhibits a considerable difference in absorbance at the 550-1150 nm region due to the absence of thiocyanate ions. Furthermore, the intensity of the broad transmittance peak at $\sim 400 \mathrm{~nm}$ differs significantly between solutions with CuSCN and $\mathrm{CuO}$ precursors. This is attributed to the lower solubility of $\mathrm{CuO}$ in aqueous $\mathrm{NH}_{3}$. The latter forms a saturated solution at $10 \mathrm{mg} \mathrm{ml}^{-1}$ that contains a smaller concentration of copper ions relative to the $\mathrm{CuSCN} / \mathrm{NH}_{3}$ solution.

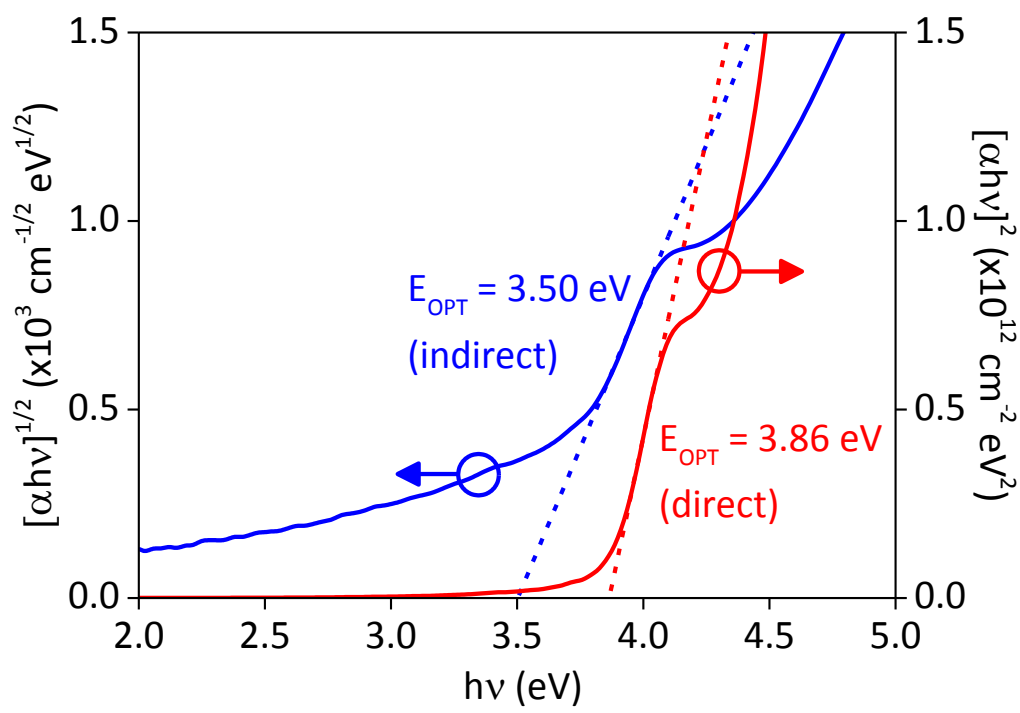

Figure S3. Plots of $(\alpha h v)^{2}$ and $(\alpha h v)^{1 / 2}$ calculated from absorbance measurements of an ammonia-processed CuSCN layer spin-cast on quartz from a $\mathrm{CuO} / \mathrm{NH}_{4} \mathrm{SCN}$ precursor formulation. From the linear regions of the plots an indirect bandgap of $3.50( \pm 0.05) \mathrm{eV}$ and a direct bandgap of $3.86( \pm 0.05) \mathrm{eV}$, were extracted.

\section{S2. Atomic Force Microscopy (AFM)}

1 layer: $R_{\text {RMS }}=1.59 \mathrm{~nm}$
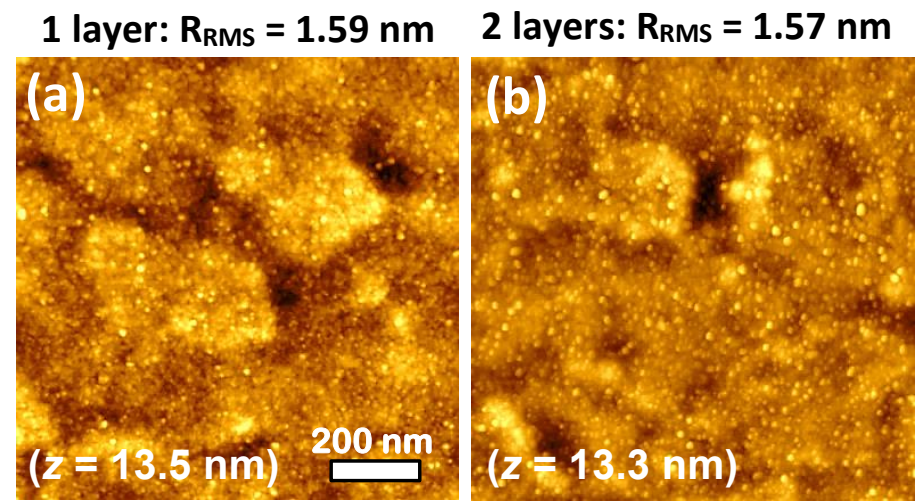

3 layers: $R_{\mathrm{RMS}}=1.53 \mathrm{~nm}$

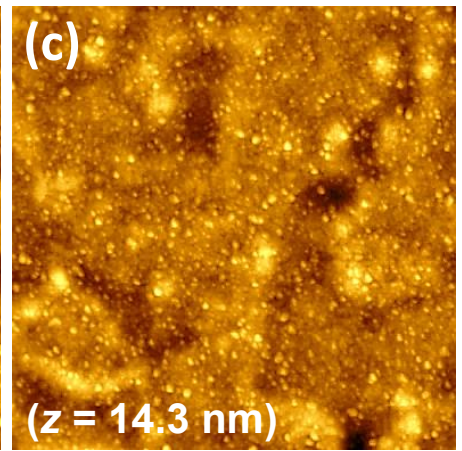

Figure S4. Topography AFM images (scan area of $1 \mu \mathrm{m}^{2}$ ) of ammonia-processed CuSCN HTLs deposited on glass/ITO. (a) The CuSCN layer was spin-cast at $2000 \mathrm{rpm}$ from a $15 \mathrm{mg}$ $\mathrm{ml}^{-1} \mathrm{CuSCN}$ precursor solution and annealed at $100{ }^{\circ} \mathrm{C}$. (b) and (c) show the topography images of CuSCN layers formed after 2 and 3, respectively, sequential spin-casting rounds of CuSCN using the same growth conditions. In all images, lighter colours correspond to higher regions 
of the surface and the specified z-values denote the maximum height relative to the minimum at $\mathrm{z}=0$.
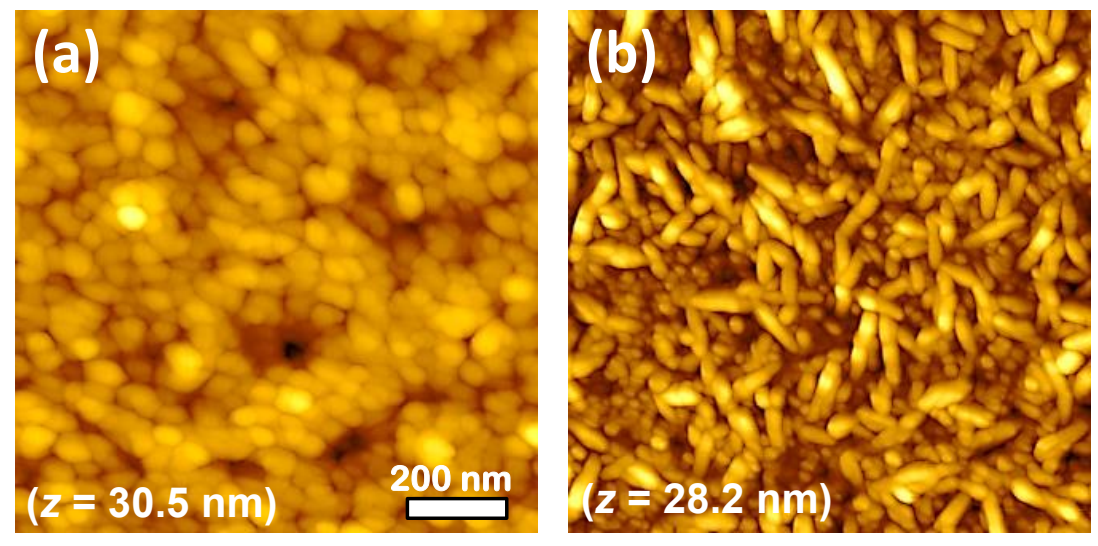

Figure S5. Topography AFM images (scan area of $1 \mu \mathrm{m}^{2}$ ) of CuSCN/DES layers spin-cast on glass at $800 \mathrm{rpm}$ from $10 \mathrm{mg} \mathrm{ml}^{-1}$ solutions and annealed at $100{ }^{\circ} \mathrm{C}$ in air. (a) A CuSCN layer that is dominated by the presence of spherical grains and exhibits surface $R_{\text {RMS }}=3.2 \mathrm{~nm}$. (b) A $\mathrm{CuSCN}$ layer that is dominated by elongated grains, where $\mathrm{R}_{\mathrm{RMS}}=3.9 \mathrm{~nm}$. Lighter colours correspond to higher regions of the surface and the specified z-values denote the maximum height relative to the minimum at $\mathrm{z}=0$.

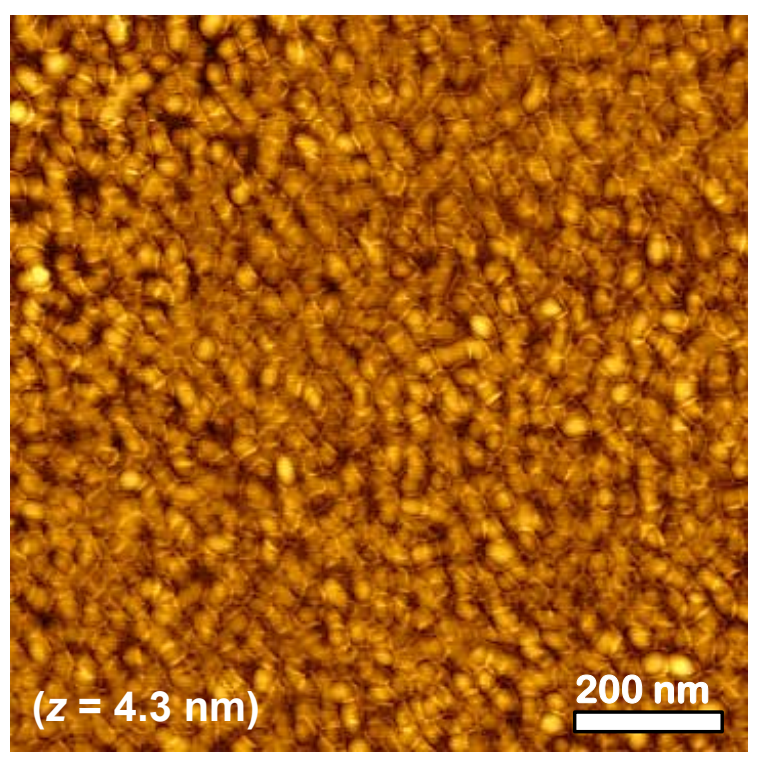

Figure S6. Topography AFM image (scan area of $1 \mu \mathrm{m}^{2}$ ) of a CuSCN layer spin-cast on glass at $800 \mathrm{rpm}$ from a solution that consisted of $\mathrm{CuO}$ and $\mathrm{NH}_{4} \mathrm{SCN}$ dissolved in aqueous ammonia. The nanocrystalline film $\left(\mathrm{R}_{\mathrm{RMS}}=0.6 \mathrm{~nm}\right)$ exhibits a similar morphology to the CuSCN layers processed from CuSCN/NH $3(a q)$. Lighter colours correspond to higher regions of the surface topography with the maximum height feature $\mathrm{z}$ being $4.3 \mathrm{~nm}$. 


\section{S3. X-ray Photoelectron Spectroscopy}

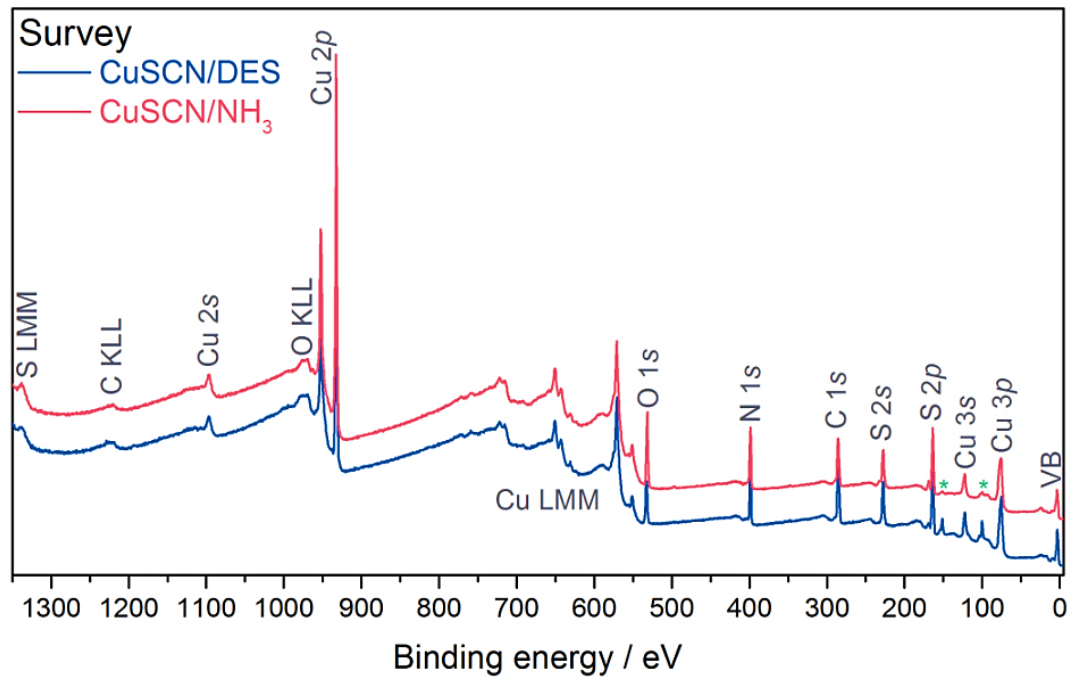

Figure S7. Survey spectra of CuSCN/DES and $\mathrm{CuSCN} / \mathrm{NH}_{3}$ indicating core levels and Auger lines. The lines at 100 and $150 \mathrm{eV}$, marked with an asterisk, correspond to the $\mathrm{Si} 2 p$ and $2 s$ core lines of the substrate.
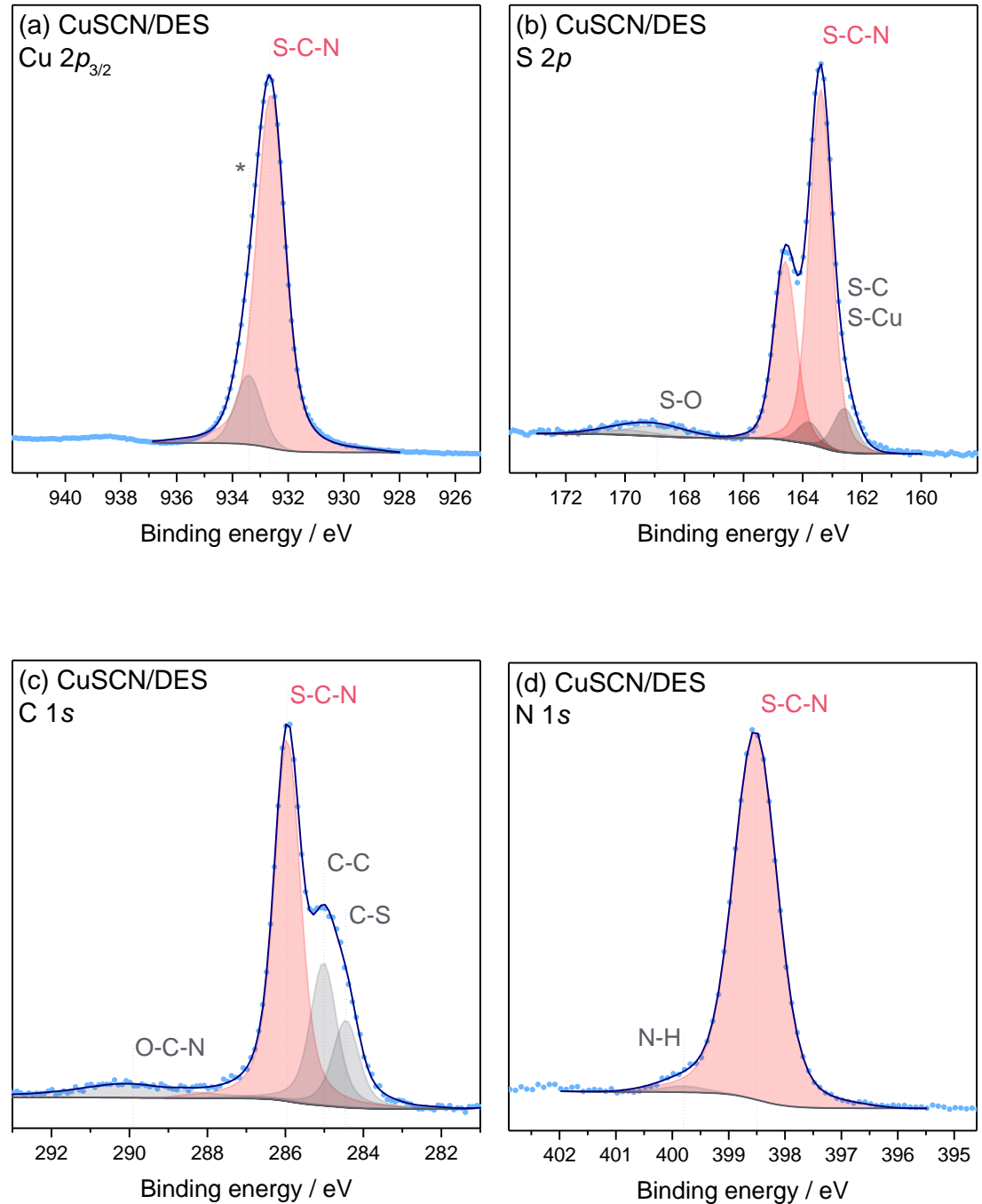
Figure S8. Peak fit analysis of the core level spectra measured for CuSCN layers processed from CuSCN/DES including: (a) $\mathrm{Cu} 2 p_{3 / 2}$, (b) $\mathrm{S} 2 p$, (c) $\mathrm{C} 1 s$, and (d) $\mathrm{N} 1 s$.
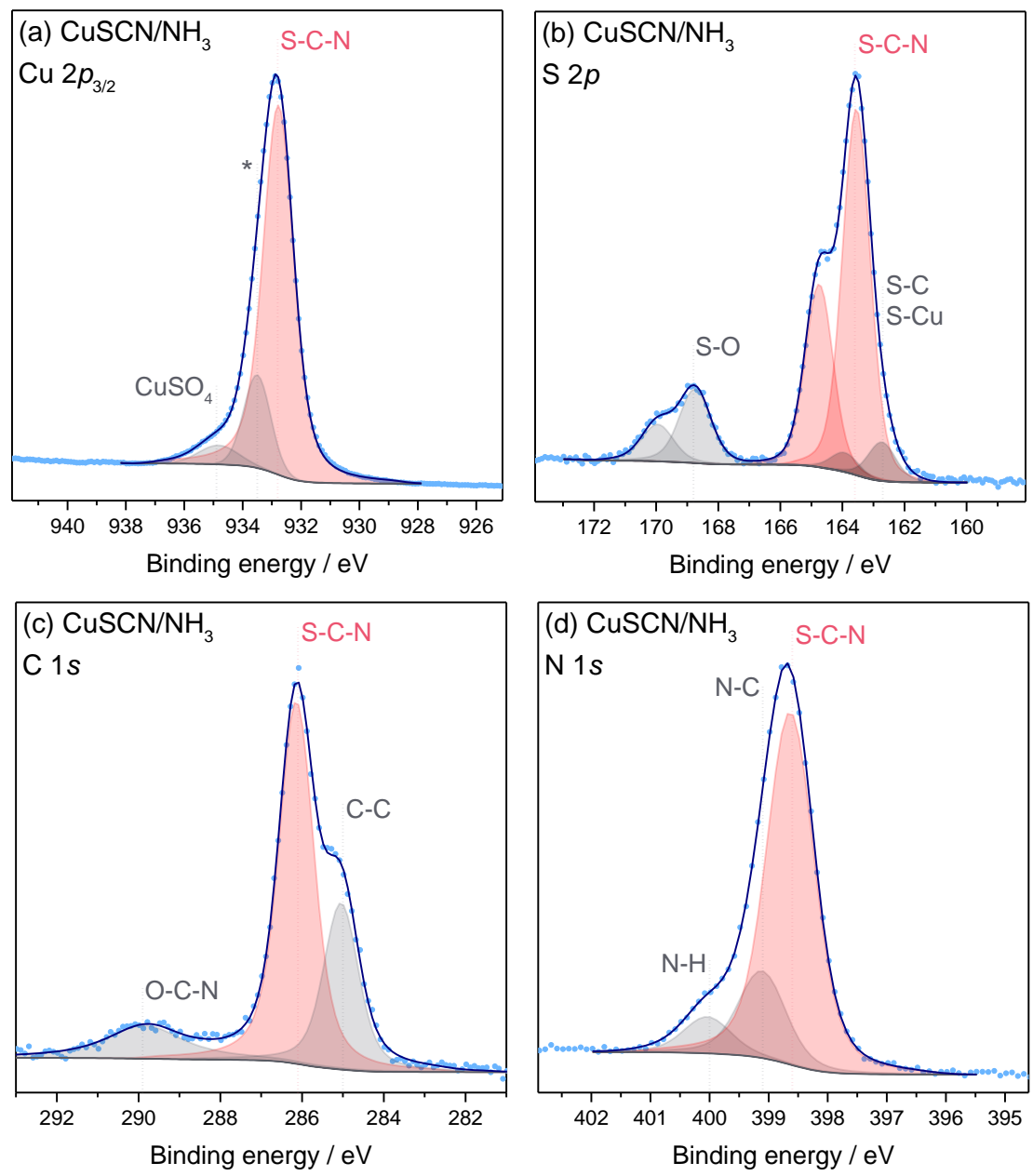

Figure S9. Peak fit analysis of the core level spectra measured for CuSCN layers processed from CuSCN/NH 3 (aq) including: (a) $\mathrm{Cu} 2 p_{3 / 2}$, (b) $\mathrm{S} 2 p$, (c) C $1 s$, and (d) $\mathrm{N} 1 s$. 


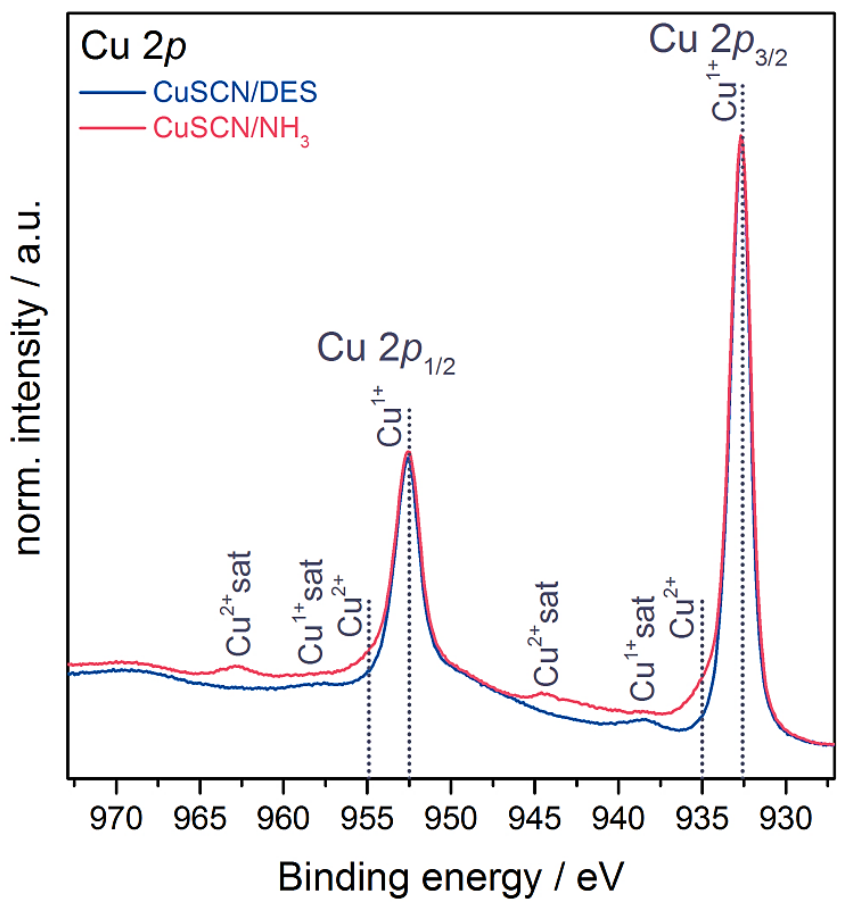

Figure S10. $\mathrm{Cu} 2 p$ core level spectra of CuSCN layers processed from CuSCN/DES and $\mathrm{CuSCN} / \mathrm{NH}_{3}(\mathrm{aq})$ solutions including satellite structures.
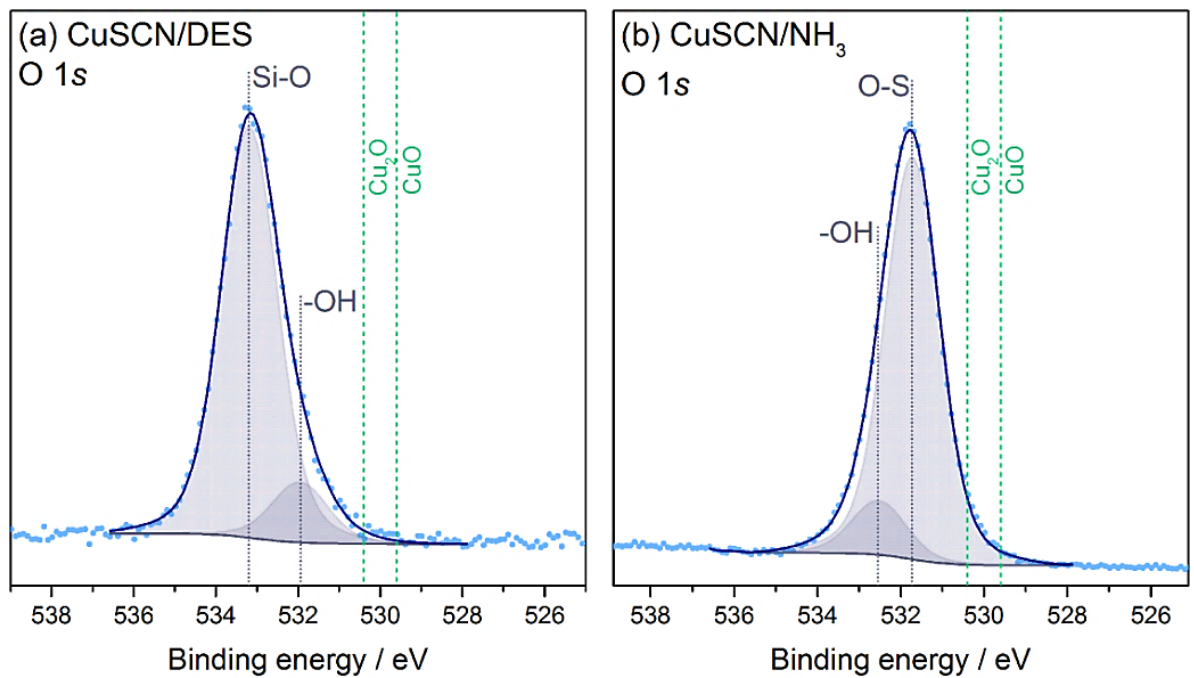

Figure S11. Peak fit analysis of the O $1 s$ core level spectra of; (a) CuSCN/DES and (b) $\mathrm{CuSCN} / \mathrm{NH}_{3}(\mathrm{aq})$. 


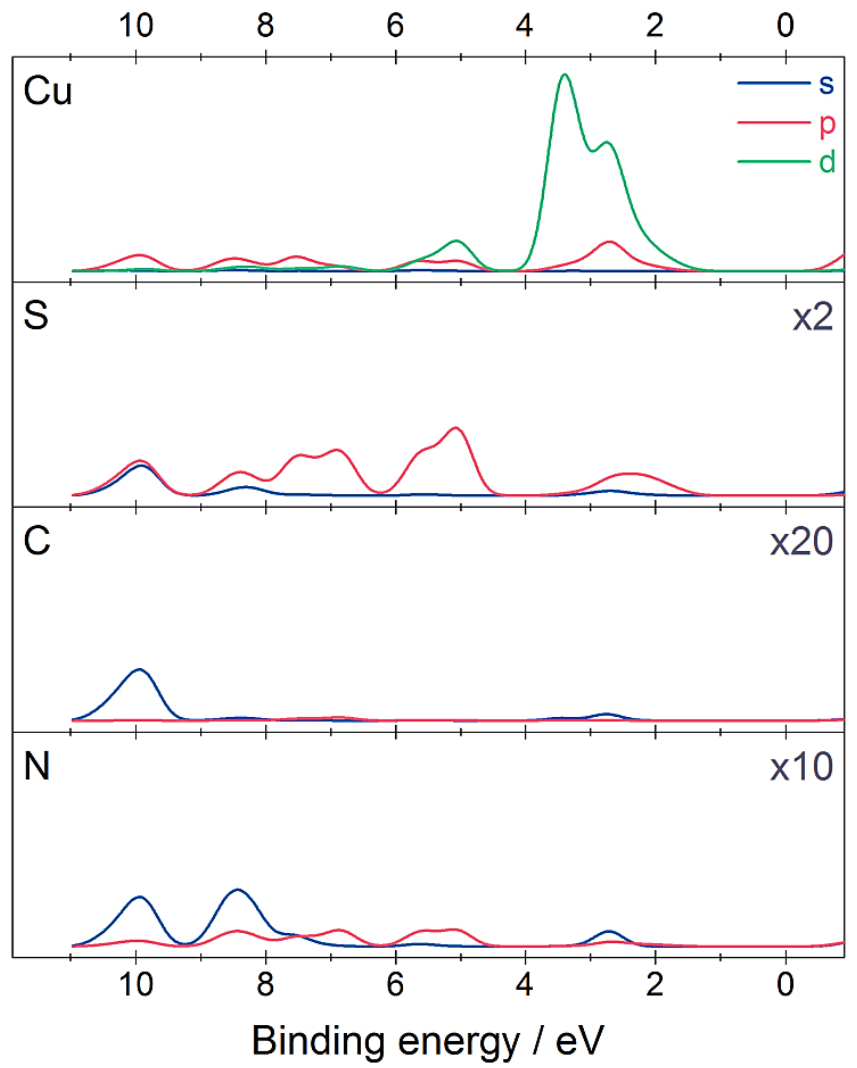

Figure S12. One electron cross section weighted partial densities of states (PDOS) for CuSCN from DFT calculations.

Table S1. Binding energy positions of core levels for both CuSCN samples from peak fit analysis of XPS data. Peaks marked with an asterisk correspond to the contribution from $\mathrm{CuSCN}$ itself.

\begin{tabular}{lcccc}
\hline Sample & $\mathrm{Cu} 2 p_{3 / 2}$ & $\mathrm{~S} 2 p_{3 / 2}$ & $\mathrm{C} 1 s$ & $\mathrm{~N} 1 s$ \\
\hline & & 162.6 & 284.5 & \\
$\mathrm{CuSCN} / \mathrm{DES}$ & $932.6^{*}$ & $163.4^{*}$ & 285.0 & $398.5^{*}$ \\
& & 168.9 & $286.0^{*}$ & 399.8 \\
& & & 290.1 & \\
\hline & & 162.7 & 285.0 & $398.6^{*}$ \\
& $932.8^{*}$ & $163.6^{*}$ & $286.1^{*}$ & 399.1 \\
& 934.9 & 168.8 & 289.9 & 400.0 \\
\hline
\end{tabular}

Table S2. Elemental ratios from peak fit analysis in atomic \% (at\%).

\begin{tabular}{lcccc}
\hline Sample & at\% Cu & at\% S & at\% C $1 s$ & at\% N $1 s$ \\
\hline $\mathrm{CuSCN} / \mathrm{DES}$ & 27.1 & 24.7 & 23.6 & 24.7 \\
\hline $\mathrm{CuSCN} / \mathrm{NH}_{3}(\mathrm{aq})$ & 33.6 & 22.5 & 21.5 & 22.3 \\
\hline
\end{tabular}




\section{S4. Electrical Characterization of Thin-Film Transistors}
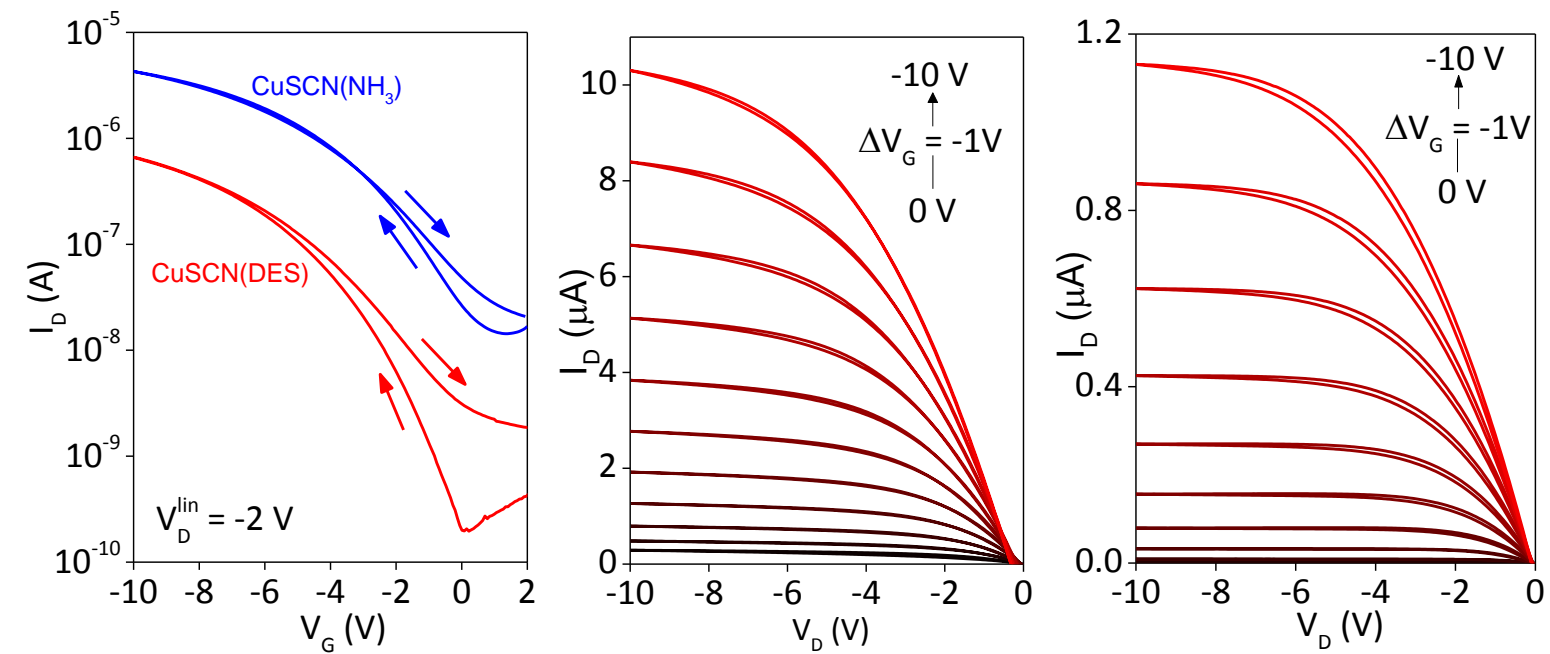

Figure S13. Electrical characteristics of TG-BC CuSCN TFTs based on P(VDF-TrFE-CFE) polymer as the gate dielectric. The TFT channel dimensions employed are $\mathrm{L}=30 \mu \mathrm{m}$ and $\mathrm{W}=$ $1000 \mu \mathrm{m}$. (left) Transfer characteristics measured in the linear regime. Output characteristics of CuSCN TFTs processed from $\mathrm{NH}_{3}$ (aq) (middle), and DES (right).
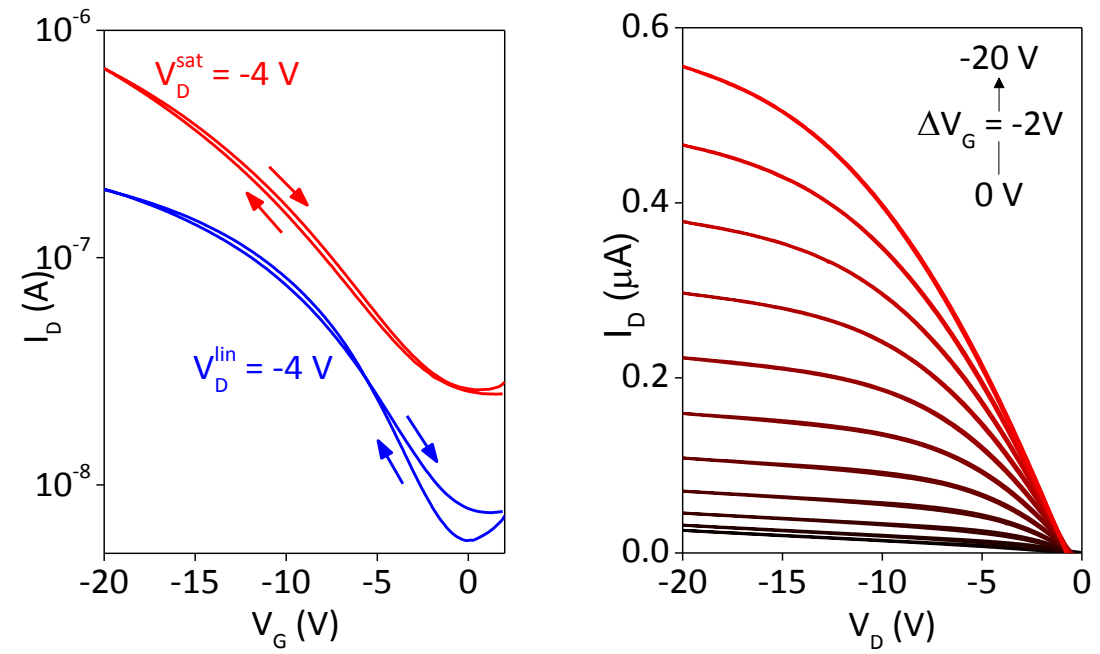

Figure S14. Electrical characterization of a TG-BC CuSCN-based TFT with a P(VDF-TrFECFE) polymer dielectric, which has channel dimensions of $\mathrm{L}=30 \mu \mathrm{m}$ and $\mathrm{W}=1000 \mu \mathrm{m}$. Transfer (Left) and output (right) characteristics of a CuSCN TFT processed from an aqueous $\mathrm{CuO} / \mathrm{NH}_{4} \mathrm{SCN}$ precursor solution. 


\section{S5. Characterization and Stability Tests of Perovskite Solar Cells}

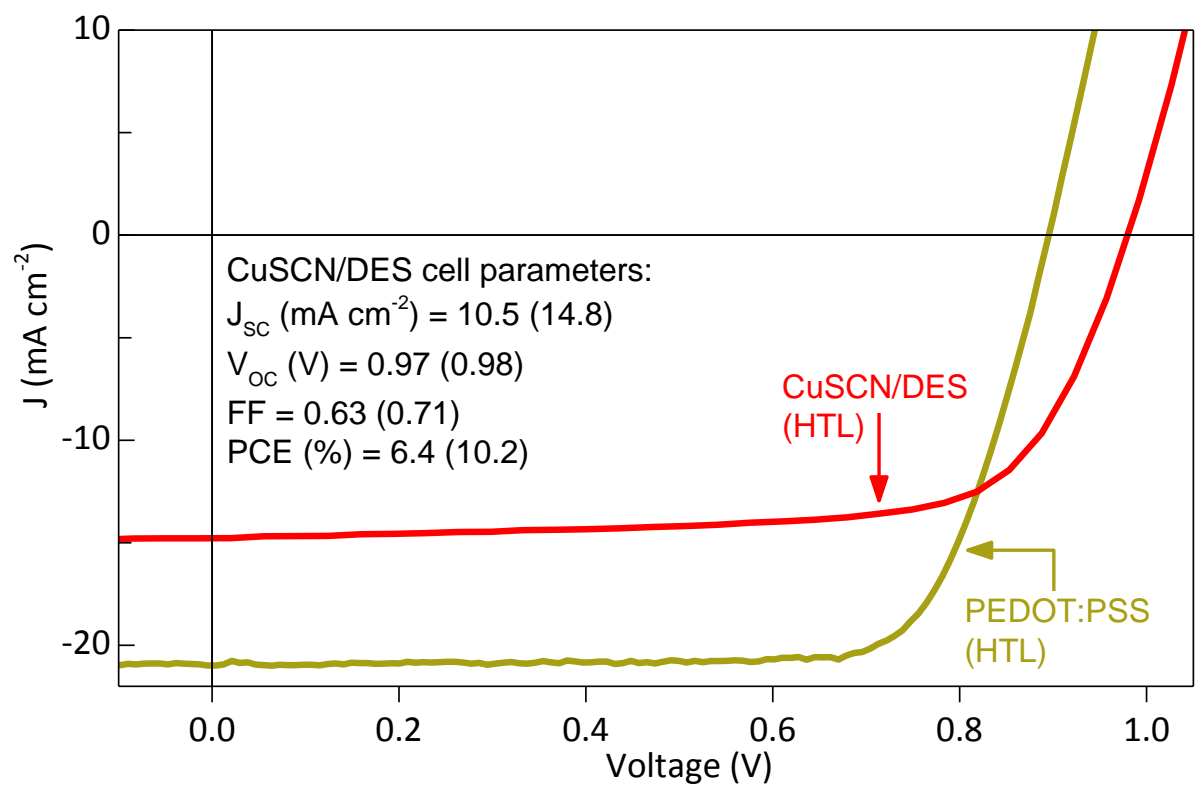

Figure S15. J-V characteristics measured under simulated 1-sun solar illumination for a $\mathrm{CH}_{3} \mathrm{NH}_{3} \mathrm{PbI}_{3}$ solar cell based on a CuSCN/DES HTL; the characteristics of an identical cell containing a PEDOT:PSS HTL is shown for comparison. Due to the low yield of devices exhibiting correct solar cell function, only a single CuSCN/DES-based device was characterised. The key parameters specified indicate the first dataset recorded, with the best of three datasets given in brackets. Solar cells with CuSCN/DES HTLs show inferior performance and lower stability relative to those with PEDOT:PSS HTLs; the physical mechanisms behind the low device stability are yet to be determined and are beyond the scope of this work.

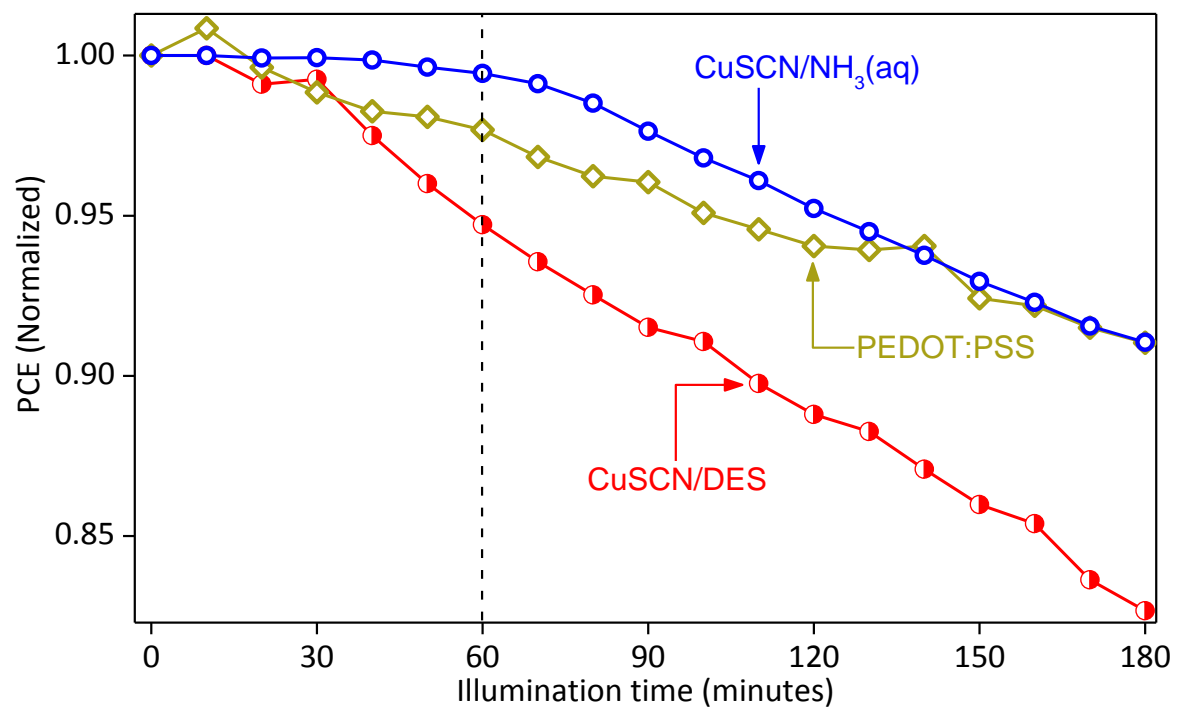

Figure S16. Normalized stability curves of $\mathrm{PCE}$ of $\mathrm{CH}_{3} \mathrm{NH}_{3} \mathrm{PbI}_{3}$ solar cells based on different HTLs. The data was recorded in a nitrogen atmosphere during a constant AM1.5 simulated solar illumination period of $3 \mathrm{~h}$. Compared to solar cells utilizing CuSCN/DES and PEDOT:PSS HTLs, devices containing CuSCN/ $\mathrm{NH}_{3}$ (aq) HTLs exhibit excellent operating stability during the first $1 \mathrm{hr}$ illumination period, and superior stability over the $3 \mathrm{~h}$ test period. Note that the data are normalised relative to the PCE value at time $=0 \mathrm{~min}$. 